\title{
Auctions with variable supply: uniform price versus discriminatory
}

\section{Working Paper}

Author(s):

Damianov, Damian S.; Becker, Johannes G.

Publication date:

2008-02

Permanent link:

https://doi.org/10.3929/ethz-a-005541937

Rights / license:

In Copyright - Non-Commercial Use Permitted

Originally published in:

Economics Working Paper Series 08/80 


\section{CER-ETH - Center of Economic Research at ETH Zurich}

\section{Auctions with Variable Supply: Uniform Price versus Discriminatory}

Damian S. Damianov and Johannes Gerd Becker

Working Paper 08/80

February 2008

\section{Economics Working Paper Series}

\section{EIH}

Eidgenössische Technische Hochschule Zürich Swiss Federal Institute of Technology Zurich 


\title{
Auctions with Variable Supply: Uniform Price versus Discriminatory
}

\author{
Damian S. Damianov* \\ University of Texas - Pan American
}

Johannes Gerd Becker $\diamond$

ETH Zürich

February 4, 2008

\begin{abstract}
We examine an auction in which the seller determines the supply after observing the bids. We compare the uniform price and the discriminatory auction in a setting of supply uncertainty. Uncertainty is caused by the interplay of two factors: the seller's private information about marginal cost, and the seller's incentive to sell the profit-maximizing quantity given the received bids. In every symmetric mixed strategy equilibrium, bidders submit higher bids in the uniform price auction than in the discriminatory auction. In the two-bidder case this result extends to the set of rationalizable strategies. As a consequence, we find that the uniform price auction generates higher expected revenue for the seller and higher trade volume.

Key Words: sealed bid multi-unit auctions, variable supply auctions, discriminatory and uniform price auctions, subgame perfect equilibria, rationalizable strategies.

JEL Classification: D44.
\end{abstract}

${ }^{*}$ Department of Economics and Finance, University of Texas - Pan American, 1201 West University Drive, Edinburg, Texas 78541-2999, USA, email: ddamianov@utpa.edu

$\diamond$ CER-ETH - Center of Economic Research at ETH Zürich, Zürichbergstrasse 18, 8032 Zürich, Switzerland, email: becker@mip.mtec.ethz.ch, http://www.cer.ethz.ch/mip 


\section{Introduction}

In a variable supply auction the seller determines the quantity to be sold after observing the bids. This form of trade has recently gained popularity in a variety of markets, e.g. markets for electricity, emission permits and initial public offerings (IPOs), yet it is most common in Treasury auctions. As noted by Nyborg, Rydqvist and Sundaresan (2002), the Treasury departments of many countries, e.g. Switzerland, Mexico, Sweden, Finland, Germany, Norway, Italy, ${ }^{1}$ adjust the quantity to be issued in response to the bidding in their regular auctions for government debt. Despite the regularity of these auctions and the high volumes traded, little is known about how ex post variations of supply affect bidding.

In this paper we examine a simple model of a variable supply auction. We explore how rational bidders behave in the uniform price and the discriminatory auction when supply is uncertain and depends on the submitted bids. Our analysis provides a ranking of these two commonly used auction formats in terms of revenue for the seller and average trading volume.

We assume that a single seller with constant marginal cost of production offers multiple units of a good to two or more buyers in an auction. Buyers are risk neutral and face uncertainty about the marginal cost of the seller. In the first stage of the game, bidders simultaneously submit their individual bids for one unit to the auctioneer. In the second stage of the game, given the received bids and the production cost, the seller decides on the supply quantity so as to maximize profit. We study two types of auctions. In the discriminatory auction, the seller acts as a perfectly discriminating monopolist with respect to the received bids, and in the uniform price auction the seller charges all winning bidders the same price determined by the lowest winning bid. ${ }^{2}$

We show that in every symmetric (mixed strategy) equilibrium buyers bid higher in the uniform price auction with a probability of one. In the two-bidder case this result holds for all rationalizable bids. As a result, the uniform pricing leads to higher expected revenue for the seller. We also find (under a convexity condition) that the uniform price auction generates higher average trade volume.

At first sight these results might seem counterintuitive: standard monopoly theory tells us that a price discriminating monopolist sells a higher quantity and realizes higher profits. The major difference here, of course, is that bidders are strategic when submitting

\footnotetext{
${ }^{1}$ See Heller and Lengwiler (2001), Umlauf (1993, pp. 316-317), Nyborg et al. (2002), Keloharju, Nyborg and Rydqvist (2005) and Rocholl (2004) for descriptions of the Treasury auction procedures in Switzerland, Mexico, Sweden, Finland and Germany, respectively. In these countries the Treasuries use a discriminatory auction and determine supply ex-post. Scalia (1997) and Bjonnes (2001) report that the Treasury auctions in Norway and Italy, respectively, are uniform price auctions with variable supply.

${ }^{2}$ In some versions of the uniform price auction the winning bidders pay the highest losing bid, but this method does not seem to have relevance in practice and we do not consider it further here.
} 
their bids. In a subgame perfect equilibrium, when bidders anticipate price discrimination, they will adjust their bids accordingly so as to counterbalance the discriminatory power of the seller. We show here that the commitment not to price discriminate in the uniform price auction will promote competition among bidders and eventually raise bid prices. As a consequence, the seller will be able to charge higher prices and sell a higher quantity.

The results of our model could serve a dual purpose. On the one hand, it offers a possible explanation of the recent empirical findings on Treasury auctions which are largely in support of uniform pricing (see Goldreich 2007, Malvey and Archibald 1998, Umlauf 1993). On the other hand, and more importantly, it could serve as a guide for future empirical research by hypothesizing that supply uncertainty causes bids to rise more in the uniform price auction than in the discriminatory auction. For instance, Nyborg et al. (2002, p.422) have already conjectured that bidder reaction to supply uncertainty is reflected in the empirical data on bidding, yet so far it has been unclear how these effects might work under the two pricing rules.

To gain intuition into how supply uncertainty affects bids in our model, we explore how increasing a bid influences the chances of winning and the payment of a bidder in uniform price and discriminatory auctions. We observe that, for both pricing rules, raising a bid raises the probability of winning. Increasing a bid, however, is less costly in the uniform price auction: whereas in the discriminatory auction winning bids are paid with a probability of one, in the uniform price auction all winners pay the lowest winning bid. So, in the uniform price auction, bidders with higher bids free ride on their lower bidding counterparts since all bidders pay the same amount. However, by submitting higher bids bidders can avoid (part of) the risk of not being served in the cases of high marginal cost in which there will be a reduction in supply. In equilibrium this creates a tendency for higher bidding in the uniform price auction.

Most closely related to our framework is the model of Lengwiler (1999), where bidders' uncertainty about seller's marginal cost is modelled in a similar fashion. Yet, Lengwiler restricts bidders' choice to the announcement of bid quantities at two exogenously given prices - high and low. He proved that the uniform price and the discriminatory auctions have perfect equilibria. Since the characterization of equilibria in such a setting is rather difficult, both auctions could not be compared in terms of revenue for the seller or efficiency.

There are two reasons why we reach here more definitive conclusions about revenue and efficiency. First, we focus on prices, which allows us to more closely examine the tradeoff between probability of winning and payment. Second, we utilize a new methodological approach. We identify bounds on the set of rationalizable bids in the two-bidder case and the set of symmetric mixed strategy equilibria in the more-than-two-bidder case. This allow us to compare the two auctions without the need to solve explicitly for the equilibria, 
which seems technically unfeasible even in this relatively simple model.

The theoretical literature on fixed supply multi-unit auctions is in favor of discriminatory pricing. The primary concern with the uniform price auction is the existence of low-price equilibria. Back and Zender (1993) extend a model first introduced by Wilson (1979) and demonstrate that there are low-price equilibria in which bidders submit kinked demand schedules. Wang and Zender (2002) find that, if submission of non-competitive bids is allowed, the uniform price auction always has equilibria with lower expected revenues than the equilibria of the discriminatory auction. Nyborg and Strebulaev (2004) develop a model allowing for short squeezes, and show that the discriminatory auction leads to more short squeezing and higher revenue than the uniform price auction.

In all these models there is no strategic role for the seller. This element, in contrast, is central to the auction games presented here and we demonstrate how it reverses the auction ranking in a strategic bidding model. Moreover our analysis does not rely on the standard argument that the uniform price auction weakens the winner's curse in common value auctions (see, e.g. Milgrom and Weber 1982), and yet the uniform price auction is found to be superior.

The paper is organized as follows. Section 2 presents the assumptions of the model and the theoretical framework. Analysis and results are in Section 3. Section 4 explores to what extent the results are applicable in more general settings, and Section 5 concludes.

\section{The model}

A monopoly seller offers multiple units of an asset to $n \geq 2$ prospective buyers. The asset has common value to buyers denoted by $v$ and the seller has no information about that common value. ${ }^{3}$ The seller will use a variable supply auction to sell the good. Each buyer $i \in\{1,2, \ldots, n\}$ is risk neutral and submits a price bid for a single unit. The monopolist observes privately his constant marginal $\operatorname{cost} c$, only the distribution of which is known to bidders. This distribution has support $[0, \bar{c}]$, where $\bar{c} \geq v$. The distribution function is denoted by $F(c)$ and its density function by $f(c)$. The latter is taken to be continuous, strictly positive in the interval $[0, \bar{c}]$ and differentiable in the interval $(0, \bar{c})$. Further, it is assumed log-concave, i.e.

$$
(\ln F(c))^{\prime}=\frac{f(c)}{F(c)}
$$

\footnotetext{
${ }^{3} \mathrm{~A}$ fully satisfactory approach would probably require that bidders have different privately observed signals of that common value. We will see that even in this simple model significant complexities arise especially in the analysis of the uniform price auction. Later we discuss that our results are robust to small asymmetries in the valuations of bidders, so this assumption is made primarily for notational clarity (for similar approach see e. g. Back and Zender 2001, Kremer and Nyborg 2004, McAdams 2007).
} 
is a monotonically decreasing function. ${ }^{4}$ We assume also that bidders are not able to pay infinitely large bid prices, that is, bids are restricted to an interval $[0, m]$, where $m>v$ is an arbitrarily large, but finite number.

In a variable supply auction, after receiving the bids, the seller decides on supply quantity so as to maximize profit. We model this scenario as a two-stage game. The payoffs of the players depend on the bids, the supply quantity and the payment rule of the auction. We first introduce some general notation for the players' payoffs and provide standard definitions of equilibrium and rationalizability for an arbitrary variable supply auction game. Then we specify these payoffs separately for the uniform price and the discriminatory auction.

\section{Pure strategies}

Each bidder $i$ submits a price bid $x_{i}$ to the auctioneer, indicating the (highest) price he is willing to pay for a unit. The vector of submitted bids is denoted by $\mathbf{x}$ and the bid vector of all bidders except bidder $i$ by $\mathbf{x}_{-i}$. Let us consider an arbitrary trade mechanism. Since the seller can condition the supply on the received bids, his strategy is a mapping from the set of bid vectors and possible values of the privately observed marginal cost $c$ into supply quantity:

$$
\phi:[0, m]^{n} \times[0, \bar{c}] \rightarrow\{0,1,2, . ., n\} .
$$

Assume that, after observing bids $\mathbf{x}$ and marginal cost $c$, the seller supplies quantity $q$. We denote seller's profit by $r_{\mathrm{S}}(\mathbf{x} ; q, c)$ and the payoff (or the net consumer surplus) of bidder $i$ by $r_{i}(\mathbf{x} ; q)$. If the seller supplies according to the strategy $\phi(\cdot)$, the expected payoff of bidder $i$ is

$$
R_{i}(\mathbf{x} ; \phi)=\int_{0}^{\bar{c}} r_{i}(\mathbf{x} ; \phi(\mathbf{x}, c)) \cdot f(c) \mathrm{d} c
$$

\section{Mixed strategies}

A mixed strategy $\sigma_{i}$ of bidder $i$ is a probability distribution over the set of pure strategies $[0, m]$. The set $\Sigma$ of mixed strategies is the set of probability distributions defined on $([0, m], \mathscr{B})$, where $\mathscr{B}$ is the Borel $\sigma$-field on $[0, m]$. A mixed strategy profile of all bidders is denoted by $\boldsymbol{\sigma}$ and a mixed strategy profile of all fellow bidders of bidder $i$ by $\boldsymbol{\sigma}_{-i}$. The

\footnotetext{
${ }^{4}$ This property of the distribution implies "monotone hazard rate", which is standard in auction theory. It guarantees in single-unit first-price auctions that bidders with higher valuations submit higher bids. It is satisfied by most common distributions: uniform, normal, logistic, chi-squared, exponential and Laplace. See Bagnoli and Bergstrom (2005) for a more complete list and for results allowing the identification of distributions with monotone hazard rates.
} 
expected payoff of bidder $i$ when bidders play mixed strategies is defined as

$$
\mathfrak{R}_{i}(\boldsymbol{\sigma} ; \phi)=\int R_{i}(\mathbf{x} ; \phi) \mathrm{d} \boldsymbol{\sigma}(\mathbf{x})
$$

If the seller has marginal cost of $c$ and bidders play mixed strategies, the seller's expected revenue is

$$
\mathfrak{R}_{\mathrm{S}}(\boldsymbol{\sigma} ; \phi(\mathbf{x}, c), c)=\int r_{\mathrm{S}}(\mathbf{x} ; \phi(\mathbf{x}, c), c) \mathrm{d} \boldsymbol{\sigma}(\mathbf{x})
$$

\section{Definitions}

We will focus on the subgame perfect equilibria in the general case and on rationalizable strategies in the special case of two bidders.

Definition 1 (subgame perfect equilibrium). The mixed strategy profile $\boldsymbol{\sigma}^{*}$ and the supply function of the seller $\phi^{*}$ constitute a subgame perfect equilibrium (short: equilibrium), if the following conditions (SS) and (MS) hold.

Second stage

For every vector of declared bids $\mathbf{x}$ and every value of the marginal costs $c$, the auctioneer sets the supply quantity so as to maximize profit:

$$
\phi^{*}(\mathbf{x}, c) \in \underset{q \in\{0,1,2, . ., n\}}{\arg \max } r_{\mathrm{S}}(\mathbf{x}, q, c) .
$$

First stage

In the first stage of the game the strategy of every bidder $i$ maximizes his expected payoff, given the strategies of the other bidders and optimal supply function of the seller:

$$
\mathfrak{R}_{i}\left(\sigma_{i}^{*}, \boldsymbol{\sigma}_{-i}^{*} ; \phi^{*}\right) \geq \mathfrak{R}_{i}\left(\sigma_{i}, \boldsymbol{\sigma}_{-i}^{*} ; \phi^{*}\right) \quad \forall \sigma_{i} \in \Sigma
$$

\section{Reduced game}

We will further on consider only optimal behavior of the seller in the second stage of the trade mechanisms we analyze. From now on we will, therefore, write

$$
\mathfrak{R}_{i}\left(\sigma_{i}, \boldsymbol{\sigma}_{-i}\right) \text { instead of } \mathfrak{R}_{i}\left(\sigma_{i}, \boldsymbol{\sigma}_{-i} ; \phi^{*}\right)
$$

always assuming that the seller supplies a profit maximizing quantity. We will similarly use $R_{i}\left(x_{i}, \mathbf{x}_{-i}\right)$ instead of $R_{i}\left(x_{i}, \mathbf{x}_{-i} ; \phi^{*}\right)$ and $\mathfrak{R}_{\mathrm{S}}(\boldsymbol{\sigma} ; c)$ instead of $\mathfrak{R}_{\mathrm{S}}\left(\boldsymbol{\sigma} ; \phi^{*}(\mathbf{x}, c), c\right)$. Condition (MS) requires that bidders' strategies constitute a Nash equilibrium in the reduced game. 
Definition 2 (rationalizable strategies). Let $\Sigma_{i}^{0}:=\Sigma$ and for each $i$ recursively define

$$
\begin{aligned}
\Sigma_{i}^{k}=\left\{\sigma_{i} \in \Sigma_{i}^{k-1}: \exists \boldsymbol{\sigma}_{-i}\right. & \in \operatorname{conv} \Sigma_{-i}^{k-1} \quad \text { such that } \\
& \left.\mathfrak{R}_{i}\left(\sigma_{i}, \boldsymbol{\sigma}_{-i}\right) \geq \mathfrak{R}_{i}\left(\sigma_{i}^{\prime}, \boldsymbol{\sigma}_{-i}\right) \quad \text { for all } \sigma_{i}^{\prime} \in \Sigma_{i}^{k-1}\right\} .
\end{aligned}
$$

conv $\Sigma_{-i}^{k-1}$ stands for the convex hull of the set $\Sigma_{-i}^{k-1}$, i.e. the smallest convex set that contains it. The set of rationalizable strategies ${ }^{5}$ for player $i$ is defined as

$$
\Sigma_{i}^{\mathrm{rat}}=\bigcap_{k=0}^{\infty} \Sigma_{i}^{k} .
$$

The rationalizable (or strategically sophisticated) strategy profiles are (mixed) strategy profiles which survive the serial deletion of strategies not belonging to the best responses of the players. Obviously, in a symmetric game the sets of rationalizable strategies for all players are equal. For notational brevity we will, therefore, omit the index $i$ and write $\Sigma^{\text {rat }}$ instead of $\Sigma_{i}^{\text {rat }}$. The set of rationalizable strategies and the set surviving the iterated deletion of strictly dominated strategies coincide in two-player games. ${ }^{6}$ This property will be useful later on when discussing the implications of Theorem 4.

\section{Analysis of the uniform price and the discrimina- tory auction}

In both the uniform and the discriminatory auction the seller orders the bids in a descending order and serves them until the supply $q$ is exhausted. Whereas in the uniform price auction all winning bidders pay a price equal to the lowest winning bid (called stopout price), in the discriminatory auction all winners are charged their own bid prices. Let us introduce some additional notation to describe the players' payoffs. Take an arbitrary bid

\footnotetext{
${ }^{5}$ For brevity and ease of access, we stick to the definition and the notation of Fudenberg and Tirole (1991, p. 49, Definition 2.3). Although this definition does not introduce the notion of a belief system as the original definition does (see Bernheim 1984, pp. 1013-1014, Definitions 3.1-3.3), it is equivalent to Bernheim's (1984) definition. The only difference is that Fudenberg and Tirole (1991) consider only games with a finite strategy space (see also Pearce 1984), whereas Bernheim (1984), similarly to the model presented here, considers a more general strategy space, which is a compact subset of an Euclidean space.

${ }^{6}$ Easily accessible proofs can be found in Fudenberg and Tirole (1991, pp. 51-52) and Pearce (1984, pp. 1048-1049, Appendix B, Lemma 3). These proofs are conducted for games with finite strategy spaces, but the claim is also valid for the compact strategy sets of our model (for this argument consult Bernheim 1984, p. 1016).
} 
vector $\mathbf{x}$. Order the bids in a descending order. For that purpose define the function

$$
\varphi_{\mathbf{x}}:\{1,2, \ldots, n\} \rightarrow\{1,2, \ldots, n\}
$$

where $\varphi_{\mathbf{x}}(j)=k$, if bidder $j$ submitted the $k$-th highest bid. If two or more bids are equal, then the function $\varphi$ orders them arbitrarily. Further we define

$$
\boldsymbol{\tau}(\mathbf{x})=\left(\tau_{1}(\mathbf{x}), \tau_{2}(\mathbf{x}), \ldots, \tau_{n}(\mathbf{x})\right)
$$

where $\tau_{k}(\mathbf{x})$ is the $k$-th highest bid if the bids are ordered in a descending order. The stopout price then is $\tau_{q}(\mathbf{x})$. The payoff of bidder $i$ in the uniform price auction is

$$
r_{i}^{U}(\mathbf{x} ; q)= \begin{cases}v-\tau_{q}(\mathbf{x}) & \text { for } \varphi_{\mathbf{x}}(i) \leq q \\ 0 & \text { for } \varphi_{\mathbf{x}}(i)>q\end{cases}
$$

The payoff of bidder $i$ in the discriminatory price auction is

$$
r_{i}^{D}(\mathbf{x} ; q)= \begin{cases}v-x_{i} & \text { for } \varphi_{\mathbf{x}}(i) \leq q, \\ 0 & \text { for } \varphi_{\mathbf{x}}(i)>q .\end{cases}
$$

The payoffs of the auctioneer in the uniform price and in the discriminatory auction are, respectively,

$$
\begin{aligned}
& r_{S}^{U}(\mathbf{x} ; q, c)=q \cdot\left(\tau_{q}(\mathbf{x})-c\right) \\
& r_{S}^{D}(\mathbf{x} ; q, c)=\sum_{j=1}^{q}\left(\tau_{j}(\mathbf{x})-c\right) .
\end{aligned}
$$

Next we start with the analysis of the two auctions.

\section{Discriminatory auction (D)}

Theorem 1. The rationalizable strategy set $\Sigma^{D}$ of the discriminatory auction contains a unique strategy for each bidder. This is a pure strategy in which every bidder submits the bid $z_{D}$, which is defined by the unique solution of the equation

$$
v-z=\frac{F(z)}{f(z)} .
$$

This is graphically illustrated in Figure 1. The proof of this theorem is quite straightforward due to the linear production cost assumption. In the discriminatory auction the seller is acting as a perfectly discriminating monopolist with respect to the submitted 
bids. Since all winning bidders have to pay their bids, all bids which exceed (or are at least not lower than) the marginal cost $c$ will be served. ${ }^{7}$

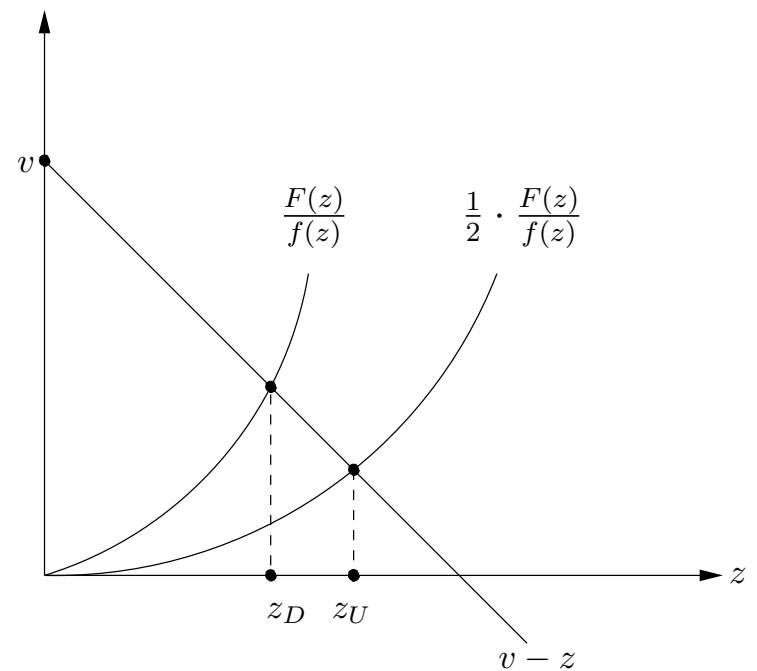

Figure 1: $z_{D}$ and $z_{U}$ are the unique solutions of the equations $(D)$ and $(U)$ (see Theorem 1 and Theorem 2).

The optimal supply quantity of the seller takes the form

$$
\phi_{\mathrm{D}}^{*}(\mathbf{x}, c)=\max \left\{k: \tau_{k}(\mathbf{x}) \geq c\right\}
$$

For the payoff of bidder $i$ we obtain

$$
r_{i}^{\mathrm{D}}\left(\mathbf{x} ; \phi_{D}^{*}\right)= \begin{cases}v-x_{i} & \text { for } x_{i} \geq c \\ 0 & \text { for } x_{i}<c\end{cases}
$$

The payoff of each bidder is independent of the other bids. The expected consumer surplus of bidder $i$ is thus

$$
R_{i}^{\mathrm{D}}(\mathbf{x})=\left(v-x_{i}\right) F\left(x_{i}\right)
$$

From the first order condition it follows that the maximizer $z_{D}$ is the unique solution of equation (D). Existence and uniqueness ${ }^{8}$ of $z_{D}$ follow from the assumption that $F(c)$ is log-concave. In the bidding stage of the game, the bid $z_{D}$ is a strongly dominant strategy

\footnotetext{
${ }^{7}$ In fact the auctioneer is indifferent between selling or not selling units to bidders who quoted a price equal to marginal cost. This detail is not important here as such an event happens with zero probability because the distribution $F(c)$ is atomless.

${ }^{8}$ Consider the function $G(z)=v-z-\frac{F(z)}{f(z)}$. Observe that $G(0)=v>0$ and $G(v)=-\frac{F(v)}{f(v)}<0(F$ is log-concave). The continuity of $G(z)$ guarantees that the equation $G(z)=0$ has a solution in the interval $(0, v)$ (by the Intermediate Value Theorem). The log-concavity of $F$ requires that $\frac{F(z)}{f(z)}$ is a monotonically increasing function, therefore $G(z)$ is strictly monotonically decreasing. Thus the equation $G(z)=0$ has a unique solution.
} 
for each player. ${ }^{9}$ Since the payoff of each bidder is independent of how other buyers bid, there is indeed no competition in the discriminatory auction. Moreover, as all bidders have the same valuation for the good, they submit equal bids, and price discrimination does not materialize. As we will show, in the same scenario the uniform price auction promotes competition among bidders.

\section{Uniform price auction (U)}

\section{The two bidder case}

In this case $\mathbf{x}=\left(x_{1}, x_{2}\right)$, and with the notation we introduced $\tau_{1}(\mathbf{x})=\max \left\{x_{1}, x_{2}\right\}$; $\tau_{2}(\mathbf{x})=\min \left\{x_{1}, x_{2}\right\}$. The payoff of the monopolist is

$$
R_{\mathrm{S}}^{\mathrm{U}}(\mathbf{x}, q, c)= \begin{cases}0 & \text { for } q=0 \\ \tau_{1}(\mathbf{x})-c & \text { for } q=1 \\ 2\left(\tau_{2}(\mathbf{x})-c\right) & \text { for } q=2\end{cases}
$$

Second stage:

The optimal supply strategy of the auctioneer is given by

$$
\phi_{\mathrm{U}}^{*}(\mathbf{x}, c)= \begin{cases}0 & \text { for } c>\tau_{1}(\mathbf{x}) \\ 1 & \text { for } \tau_{1}(\mathbf{x})>c>2 \cdot \tau_{2}(\mathbf{x})-\tau_{1}(\mathbf{x}) \\ 2 & \text { for } 2 \cdot \tau_{2}(\mathbf{x})-\tau_{1}(\mathbf{x})>c\end{cases}
$$

The equalities occur with probability 0 and are therefore omitted.

First stage:

Now we can characterize the expected payoff of bidder $i$ :

$$
\begin{aligned}
& R_{i}^{\mathrm{U}}\left(x_{i}, x_{-i}\right) \\
& \quad= \begin{cases}\left(v-x_{i}\right) \cdot\left(F\left(x_{i}\right)-F\left(2 x_{-i}-x_{i}\right)\right)+\left(v-x_{-i}\right) \cdot F\left(2 x_{-i}-x_{i}\right) & \text { for } x_{i} \geq x_{-i}, \\
\left(v-x_{i}\right) \cdot F\left(2 x_{i}-x_{-i}\right) & \text { for } x_{i}<x_{-i} .\end{cases}
\end{aligned}
$$

The next Theorem establishes several important properties of the expected payoff function. See Figures 1 and 2 for graphical illustrations of these properties.

\footnotetext{
${ }^{9}$ Bidding $z_{D}$ maximizes the the buyer's expected surplus, so one might be tempted to think that the seller expected revenue must be minimal for the discriminatory auction. As we will see, however, these auctions are not zero-sum games because they lead to different average trading volumes, and thus different social surplus. So, a ranking cannot be provided on the basis of such an argument.
} 
Theorem 2. The expected profit function has the following properties; $\partial_{i}^{+} R_{i}^{\mathrm{U}}\left(x_{i}, x_{-i}\right)$ denotes the partial derivative from above with respect to $x_{i}$ :

(i) $R_{i}^{\mathrm{U}}\left(x_{i}, x_{-i}\right)$ is continuous in $\left(x_{i}, x_{-i}\right)$,

(ii) $R_{i}^{\mathrm{U}}\left(x_{i}, x_{-i}\right)=0 \quad$ for $\quad 0 \leq x_{i} \leq x_{-i} / 2$,

(iii) $\partial_{i}^{+} R_{i}^{\mathrm{U}}\left(x_{i}, x_{-i}\right)>0 \quad$ for $\quad x_{i}=x_{-i}<v$,

(iv) $\partial_{i} R_{i}^{\mathrm{U}}\left(x_{i}, x_{-i}\right)>0 \quad$ for $\quad \frac{x_{-i}}{2}<x_{i}<\min \left\{x_{-i}, z_{U}\right\}$, where $z_{U}$ is the unique solution of the equation

$$
v-z=\frac{1}{2} \cdot \frac{F(z)}{f(z)}
$$

(v) There exists $\delta>0$ such that

$$
\partial_{i} R_{i}^{\mathrm{U}}\left(x_{i}, x_{-i}\right)>0 \quad \text { for } \quad x_{-i}<x_{i}<\min \left\{x_{-i}+\delta, z_{U}\right\} .
$$

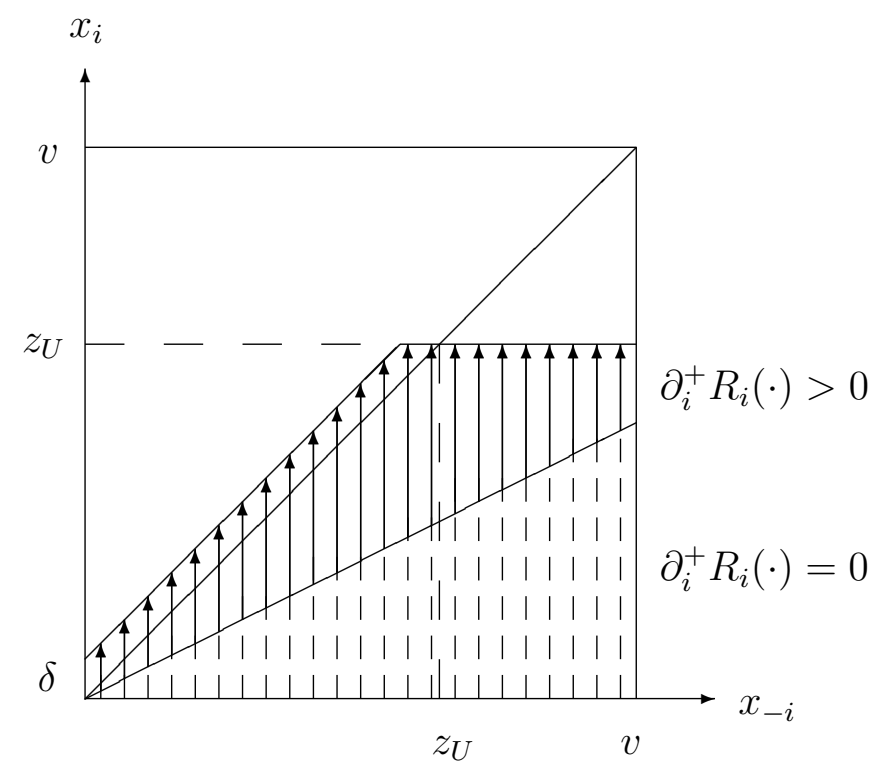

Figure 2: In the dash-line area the payoff of bidder $i$ is zero (see property (ii)). In the vector area the bidder's payoff increases in the direction of the arrows (see properties (iii), (iv) and (v)).

\section{Proof.}

Statements (i) and (ii) follow directly from equation (3.1). To prove (i) observe that for $x_{i}=x_{-i}$ both lines in (3.1) are equal to $\left(v-x_{i}\right) \cdot F\left(x_{i}\right)$. The intuition behind (ii) is simple. If $0 \leq x_{i} \leq x_{-i} / 2$, it is not profitable for the seller to service bidder $i$ for any realization of the marginal cost $c$, which means that with a probability of one bidder $i$ is not served. 
To prove statement (iii) note that for $x_{i}=x_{-i}$ we obtain

$$
\begin{aligned}
\partial_{i}{ }^{+} R_{i}^{\mathrm{U}}\left(x_{i}, x_{-i}\right)= & \left(v-x_{i}\right) \cdot\left(f\left(x_{i}\right)+f\left(2 x_{-i}-x_{i}\right)\right)-F\left(x_{i}\right) \\
& +F\left(2 x_{-i}-x_{i}\right)-\left(v-x_{-i}\right) \cdot f\left(2 x_{-i}-x_{i}\right) \\
= & \left(v-x_{i}\right) \cdot f\left(x_{i}\right)>0 .
\end{aligned}
$$

Statement (iv) follows from the (in)equalities

$$
\begin{aligned}
\partial_{i} R_{i}^{\mathrm{U}}\left(x_{i}, x_{-i}\right) & =\left(v-x_{i}\right) \cdot f\left(2 x_{i}-x_{-i}\right) \cdot 2-F\left(2 x_{i}-x_{-i}\right) \\
& =2 f\left(2 x_{i}-x_{-i}\right)\left[\left(v-x_{i}\right)-\frac{F\left(2 x_{i}-x_{-i}\right)}{2 f\left(2 x_{i}-x_{-i}\right)}\right] \\
& >2 f\left(2 x_{i}-x_{-i}\right)\left[\left(v-x_{i}\right)-\frac{F\left(x_{i}\right)}{2 f\left(x_{i}\right)}\right] \\
& >2 f\left(2 x_{i}-x_{-i}\right)\left[\left(v-z_{U}\right)-\frac{F\left(z_{U}\right)}{2 f\left(z_{U}\right)}\right]=0 .
\end{aligned}
$$

Notice that the last two inequalities apply because, as assumed, $\frac{F}{f}$ is a monotonically increasing function. A rigorous proof of property ( $\mathrm{v}$ ) can be found in Appendix A. Here we illustrate only the main idea. We exploit the already established properties (i) and (iii) and the fact that pre-images of open sets under continuous mappings are open to reach the conclusion that in an open neigborhood around the set

$$
\left\{\left(x_{i}, x_{-i}\right) \mid x_{i}=x_{-i}<z_{U}\right\}
$$

the partial derivative from above with respect to $x_{i}$ is positive. The claim follows.

As a consequence of Theorem 2 and equation (3.1) we obtain the statement:

Corollary 1. The (pure strategy) best response correspondence $x_{i}^{*}$ of each bidder $i$, has the following properties:

$$
\begin{gathered}
x_{-i} \notin x_{i}^{*}\left(x_{-i}\right), \\
x_{i}^{*}(0)=\left\{z_{D}\right\}, \\
x_{i}<v \quad \text { for all } \quad x_{i} \in x_{i}^{*}(v) .
\end{gathered}
$$

Proof. (3.2) follows from (iii); (3.3) and (3.4) follow from (3.1).

(3.2) implies that the uniform price auction has no symmetric subgame perfect equilibrium in pure strategies. (3.3) and (3.4) further imply that the best response correspondence is not continuous, which points to the generic difficulty for the existence of pure strategy equilibria. Indeed, if the best response were continuous, it should cross the $45^{\circ}$ line, which does not happen here because of (3.2). In subsection 3 we calculate the best response for 
an example of uniformly distributed marginal cost. See Figure 6 for an illustration of the best response correspondences for that numerical example. The next Theorem provides an equilibrium existence result.

Theorem 3 (equilibrium existence). The uniform price auction has a mixed strategy equilibrium.

Proof. The existence is guaranteed by Glicksberg's (1952) theorem, since the expected payoff function $R_{i}^{\mathrm{U}}\left(x_{i}, x_{-i}\right)$ is continuous (see property (i)) and the support $[0, m]$ of the bids is a convex and compact set.

Theorem 4 (rationalizable strategies). The set of rationalizable strategies of the uniform price auction contains only mixed strategies with support in the interval $\left[z_{U}, v\right]$ :

$$
\sigma\left(\left[z_{U}, v\right]\right)=1 \quad \text { for all } \quad \sigma \in \Sigma^{U} \text {. }
$$

As remarked earlier, the Theorem applies also for the sets of mixed strategies which survive the serial deletion of strongly dominated strategies. One can easily check $^{10}$ that $z_{U}>z_{D}$; therefore, it follows from Theorems 1 and 4 that the rationalizable bids in the uniform price auction are (almost surely) higher than those in the discriminatory auction. Before providing a proof of Theorem 4, let us explain why rational players bid higher in the uniform price auction. Consider the case in which bidder $i$ submitted a bid at least as high as his fellow bidder $\left(x_{i} \geq x_{-i}\right)$ and let us compare the changes in his payoff resulting from an increase of his bid under the two pricing rules. In both auction formats the winning probability $F\left(x_{i}\right)$ will clearly increase equally. While in the discriminatory auction the bidder has to pay his new bid with a probability of one, in the uniform price auction he pays on average less: he pays the bid price of his fellow bidder when both bidders are served. In this case, increasing his bid is more profitable (or at least less unprofitable) under the uniform pricing rule. Consider now the case $\left(x_{i}<x_{-i}\right)$. In this scenario bidder $i$ is served with higher probability under the discriminatory than under the uniform price auction: $F\left(x_{i}\right)>F\left(2 x_{i}-x_{-i}\right)$. Therefore, in the uniform price auction this bidder will want to compensate for this lower probability by increasing his bid. This very characteristic of the uniform price payment rule creates incentives for higher bidding. We now move on to provide the main idea of the proof of the Theorem 4. The rigorous but more technical proof can be found in Appendix A.

Sketch of proof of Theorem 4 (rationalizable strategies).

It is intuitive that rational players do not bid higher than their valuation (see Part 1 of the proof in Appendix A). The more interesting part is to show that bidders do not bid

\footnotetext{
${ }^{10}$ This follows directly from the fact that $z_{D}$ solves equation (D), $z_{U}$ solves equation $(U)$, and $F(c)$ is log-concave (see Figure 1).
} 
below $z_{U}$. Property (v) of Theorem 2 reads:

There exists $\delta>0$ such that

$$
\partial_{i} R_{i}^{\mathrm{U}}\left(x_{i}, x_{-i}\right)>0 \quad \text { for } \quad x_{-i}<x_{i}<\min \left\{x_{-i}+\delta, z_{U}\right\}
$$

This property is depicted in Figure 2, where we can see that in a small neighborhood above the $45^{\circ}$ line the payoff of bidder $i$ is increasing in his bid. We use now this property to state:

Bidders who play rationalizable strategies do not bid below $z_{U}$, i.e.

$$
\sigma\left(\left[0, z_{U}\right]\right)=0 \quad \text { for all } \quad \sigma \in \Sigma^{U}
$$

The proof of this statement is relegated to Appendix A (see Part 2 of the proof therein). The idea is to divide the interval $\left[0, z_{U}\right)$ into small intervals of length $\delta$ (in the sense of statement (v) of Theorem 2), where $z_{U} / \delta=N$ is an integer number. We denote the intervals

$$
I_{k}=[(k-1) \cdot \delta, k \cdot \delta) \quad \text { for } \quad k=1,2, \ldots N ; \quad I_{0}=\emptyset
$$

as illustrated in Figure 3. By an iterative procedure we show that mixed strategies placing positive probability on $I_{1}, I_{2}, \ldots, I_{N}$ are not rationalizable. For that purpose we use the properties of bidders' payoff functions as stated in Theorem 2.

\section{The general case}

In this subsection we discuss the case in which an arbitrary number of $n \geq 2$ bidders participate in the uniform price auction. We formally derive bidders' payoff function and show that it is continuous in the vector of declared bids (see Lemma 1). This finding is used to verify that the uniform price auction has a symmetric mixed strategy equilibrium (Theorem 5).

We further prove that in a symmetric equilibrium bids in the uniform price auction are with a probability of one higher than bids in the discriminatory auction (Theorem 6).

First, we derive bidders' payoff function. Let $\mathbf{x}$ be an arbitrary bid vector and $q, q^{\prime} \in$ $\{0, \ldots, n\}$. Define $\tau_{0}(\mathbf{x}):=v$. The seller weakly prefers to sell $q$ instead of $q^{\prime}$ units if and only if

$$
\left(\tau_{q}(\mathbf{x})-c\right) \cdot q \geq\left(\tau_{q^{\prime}}(\mathbf{x})-c\right) \cdot q^{\prime}
$$




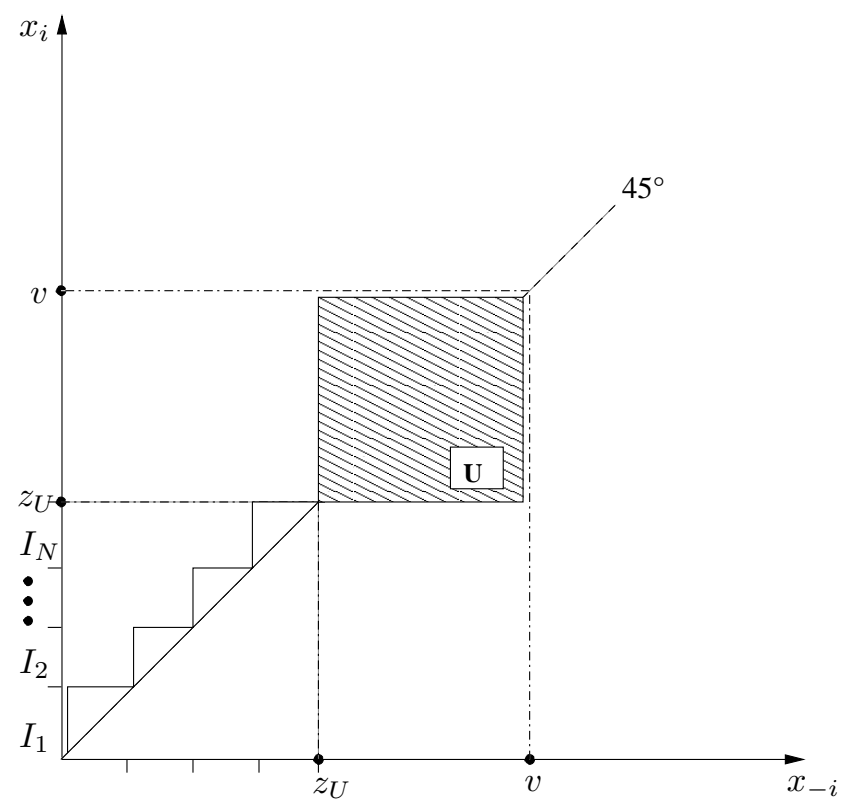

Figure 3: The dark colored rectangle depicts the boundaries of the support of the rationalizable strategies in the uniform price auction. The triangles illustrate the serial elimination of mixed strategies placing positive probability on the intervals $I_{1}, I_{2}, \ldots, I_{N}$.

Thus the seller will not supply more than $q$ units if and only if

$$
c \geq c_{q}^{-}(\mathbf{x}):= \begin{cases}\max _{q<q^{\prime} \leq n} \frac{q \cdot \tau_{q}(\mathbf{x})-q^{\prime} \cdot \tau_{q^{\prime}}(\mathbf{x})}{q-q^{\prime}} & \text { for } q<n, \\ 0 & \text { for } q=n .\end{cases}
$$

He will not supply less than $q$ units if and only if

$$
c \leq c_{q}^{+}(\mathbf{x}):= \begin{cases}\min _{0 \leq q^{\prime}<q} \frac{q \cdot \tau_{q}(\mathbf{x})-q^{\prime} \cdot \tau_{q^{\prime}}(\mathbf{x})}{q-q^{\prime}} & \text { for } q \geq 1, \\ \bar{c} & \text { for } q=0 .\end{cases}
$$

So, the seller optimally supplies the quantity $q$ for $c \in\left[c_{q}^{-}, c_{q}^{+}\right]$. The set of winners is then $\left\{j \mid \varphi_{\mathbf{x}}(j) \leq q\right\}$, and all winners pay the stopout price $\tau_{q}(\mathbf{x})$. The expected payoff of an arbitrary bidder $i$ is thus

$$
R_{i}^{\mathrm{U}}(\mathbf{x})=\sum_{q=0}^{n}\left(v-\tau_{q}(\mathbf{x})\right) \cdot P(q ; \mathbf{x}) \cdot \mathbb{1}_{\left\{\varphi_{\mathbf{x}}(i) \leq q\right\}},
$$

where

$$
P(q ; \mathbf{x}):=\operatorname{Prob}\left(c_{q}^{+}(\mathbf{x})>c>c_{q}^{-}(\mathbf{x})\right)=\max \left\{F\left(c_{q}^{+}(\mathbf{x})\right)-F\left(c_{q}^{-}(\mathbf{x})\right), 0\right\}
$$


is the probability that exactly $q$ units are sold. Now we can state:

Lemma 1 (continuity). $R_{i}^{\mathrm{U}}(\mathbf{x})$ is continuous in $\mathbf{x}$.

See Appendix A for a proof.

Theorem 5 (existence). The uniform price auction has a symmetric mixed strategy equilibrium.

The Theorem follows immediately from Becker and Damianov (2006). There it is shown that symmetric games with continuous payoffs and compact and convex strategy spaces possess symmetric mixed strategy equilibria. Now we can formulate our main result for the general case:

Theorem 6. In every symmetric equilibrium $\boldsymbol{\sigma}_{U}^{*}$ of the uniform price auction, bids are almost always higher than in the discriminatory auction:

$$
\sigma_{U}^{*}\left(\left(z_{D}, v\right]\right)=1
$$

Sketch of the proof. Although the idea of the proof is simple, the proof itself is quite technical and lengthy. It is relegated to Appendix B. Here we provide only the basic intuition and sketch the most important argument. It is clear that in every symmetric mixed strategy equilibrium buyers do not bid higher than their valuation. The more interesting part is to show that in every symmetric equilibrium buyers bid almost surely higher than $z_{D}$. We denote by $z_{*}$ the lower bound of the support of a symmetric mixed strategy equilibrium:

$$
z_{*}=\max \left\{z \mid \sigma_{U}^{*}([z, v])=1\right\} .
$$

The proof proceeds by contradiction. We assume that there exists a symmetric mixed strategy equilibrium for which $z_{*} \leq z_{D}$. We consider a deviation strategy of an arbitrary bidder $i$, which shifts the probability mass of an interval $Z_{*}^{\varepsilon}:=\left[z_{*}, z_{*}+\varepsilon\right)$ to the point $z_{*}+\varepsilon$ and show that for a sufficiently small $\varepsilon>0$ the deviation is profitable. Thus we reach a contradiction to the equilibrium assumption.

\section{Revenue and average trade volume}

Theorem 4 states that the supports of the rationalizable strategy sets in the uniform price and the discriminatory auction are disjoint in the two-bidder case. In Theorem 6, we further argue that in the general case the supports of the symmetric mixed strategy eqilibrium sets in the two auctions are disjoint. Bidders submit higher bids in the uniform price auction with a probability of one. As a consequence of these Theorems, we obtain a ranking of the auction formats in terms of revenue for the auctioneer and efficiency. 


\section{Revenue}

Theorem 7 (revenue). For any given value of the marginal cost $c$, the expected revenue of the uniform price auction is at least as high as that of the discriminatory auction:

(a) for all rationalizable strategies in the two-bidder case

$$
\mathfrak{R}_{\mathrm{S}}^{U}\left(\boldsymbol{\sigma}_{U} ; c\right) \geq \mathfrak{R}_{\mathrm{S}}^{D}\left(\boldsymbol{\sigma}_{D} ; c\right) \text { for } n=2 \text { and all } \boldsymbol{\sigma}_{D} \in\left(\Sigma^{D}\right)^{n}, \boldsymbol{\sigma}_{U} \in\left(\Sigma^{U}\right)^{n} \text {, }
$$

(b) for all symmetric mixed strategy equilibria in the general case

$$
\mathfrak{R}_{\mathrm{S}}^{U}\left(\boldsymbol{\sigma}_{U}^{*} ; c\right) \geq \mathfrak{R}_{\mathrm{S}}^{D}\left(\boldsymbol{\sigma}_{D}^{*} ; c\right) \quad \text { for } n \geq 2
$$

Expected revenue in the uniform price auction is strictly higher when positive quantities of the good are traded.

Proof. The uniform price auction generates higher expected revenue because bids are higher. For $c<z_{D}$ positive quantities will be traded both in the uniform price and the discriminatory auction. In this case we can prove $\left(R_{n}\right)$ by using Theorems 6 and 1 :

$$
\mathfrak{R}_{\mathrm{S}}^{U}\left(\boldsymbol{\sigma}_{U}^{*} ; c\right)>r_{S}^{U}\left(z_{D}, \ldots, z_{D} ; c\right)=r_{S}^{D}\left(z_{D}, \ldots, z_{D} ; c\right)=\mathfrak{R}_{\mathrm{S}}^{D}\left(\boldsymbol{\sigma}_{D}^{*} ; c\right)
$$

The proof of $\left(R_{2}\right)$ is analogous; apply Theorems 4 and 1 . For $c>z_{D}$ there will be no trade in the discriminatory auction. If there are bids in the uniform price auction, which exceed $c$, then at least one of them will be served, and the uniform price auction will again be strictly more profitable. If all bids in the uniform price auction are below $c$, then there will be no trade in the two auction formats. This is the only case in which the uniform price and the discriminatory auction will generate the same revenue.

\section{Average trade volume}

The average trading quantity ${ }^{11}$ resulting from the mixed strategy profile $\boldsymbol{\sigma}(\mathbf{x})$ is given as follows:

$$
\mathfrak{Q}(\boldsymbol{\sigma})=\int Q(\mathbf{x}) \mathrm{d} \boldsymbol{\sigma}(\mathbf{x})
$$

where

$$
Q(\mathbf{x})=\int_{0}^{v} \phi^{*}(\mathbf{x}, c) \cdot f(c) \mathrm{d} c .
$$

\footnotetext{
${ }^{11}$ Average trading quantity can be taken in this setting also as an efficiency measure. Note that buyers are only served when $v \geq c$ since they submit bids not higher than $v$ and the seller does not serve bids below $c$. This means that trade takes place only when desirable ex-post. The mechanism which induces a higher probability for sale, i.e. higher average turnover, can, therefore, be considered as the more efficient mechanism. We have to point out, however, that higher average turnover does not necessarily imply higher efficiency in Pareto sense or ex-ante higher sum of the surplus of market participants.
} 
Theorem 8 (average trade quantity). If the marginal cost distribution function is convex $\left(F^{\prime \prime} \geq 0\right)$, the average trade quantity in the uniform price auction is higher than that in the discriminatory auction:

(a) for all rationalizable strategies in the two-bidder case

$$
\mathfrak{Q}^{U}\left(\boldsymbol{\sigma}_{U}\right)>\mathfrak{Q}^{D}\left(\boldsymbol{\sigma}_{D}\right) \quad \text { for } \quad n=2 \quad \text { and all } \boldsymbol{\sigma}_{D} \in\left(\Sigma^{D}\right)^{n}, \boldsymbol{\sigma}_{U} \in\left(\Sigma^{U}\right)^{n}
$$

(b) for all symmetric mixed strategy equilibria in the general case

$$
\mathfrak{Q}^{U}\left(\boldsymbol{\sigma}_{U}^{*}\right)>\mathfrak{Q}^{D}\left(\boldsymbol{\sigma}_{D}^{*}\right) \quad \text { for } n \geq 2 \text {. }
$$

Proof. Recall that $P(q ; \mathbf{x})$ denotes the probability with which the seller will sell quantity $q$ if the vector of bids is $\mathbf{x}$. The average quantity sold in the uniform price auction can be expressed as a function of the ordered bids:

$$
Q_{U}(\mathbf{x})=Q_{U}(\boldsymbol{\tau}(\mathbf{x}))=\sum_{q=1}^{n} q \cdot P(q ; \mathbf{x})=\sum_{\left\{q \mid c_{q}^{+}>c_{q}^{-}\right\}} q \cdot P(q ; \mathbf{x})
$$

The last equality implies that we need to sum only over the elements $\tau_{q}(\mathbf{x})$ for which $c_{q}^{+}>c_{q}^{-}$, as otherwise $P(q ; \mathbf{x})=0$. We write these quantities in an ascending order $l_{1}, l_{2}, \ldots, l_{h}$ and obtain

$$
\tau_{l_{1}}(\mathbf{x})>\tau_{l_{2}}(\mathbf{x})>\cdots>\tau_{l_{h}}(\mathbf{x}) .
$$

For the sake of brevity, we will further write $\tau_{l_{k}}$ instead of $\tau_{l_{k}}(\mathbf{x})$. We will show that

$$
Q_{U}\left(\tau_{l_{1}}, \tau_{l_{2}}, \ldots, \tau_{l_{h}}\right) \geq Q_{U}\left(\tau_{l_{2}}, \tau_{l_{2}}, \ldots, \tau_{l_{h}}\right)
$$

We observe that $c_{l_{1}}^{-}=c_{l_{2}}^{+}$and recall that $c_{l_{1}}^{-}$is a solution of the equation

$$
l_{1} \cdot\left(\tau_{l_{1}}-c_{l_{1}}^{-}\right)=l_{2} \cdot\left(\tau_{l_{2}}-c_{l_{1}}^{-}\right),
$$

which means that the two dark rectangles in Figure 4 cover equal areas. Equation (3.6) is equivalent to

$$
\frac{\tau_{l_{1}}-c_{l_{1}}^{-}}{\tau_{l_{2}}-c_{l_{1}}^{-}}=\frac{l_{2}}{l_{1}}
$$

From the convexity of $F$ it follows that

$$
\frac{F\left(\tau_{l_{1}}\right)-F\left(c_{l_{1}}^{-}\right)}{F\left(\tau_{l_{2}}\right)-F\left(c_{l_{1}}^{-}\right)} \geq \frac{\tau_{l_{1}}-c_{l_{1}}^{-}}{\tau_{l_{2}}-c_{l_{1}}^{-}}
$$




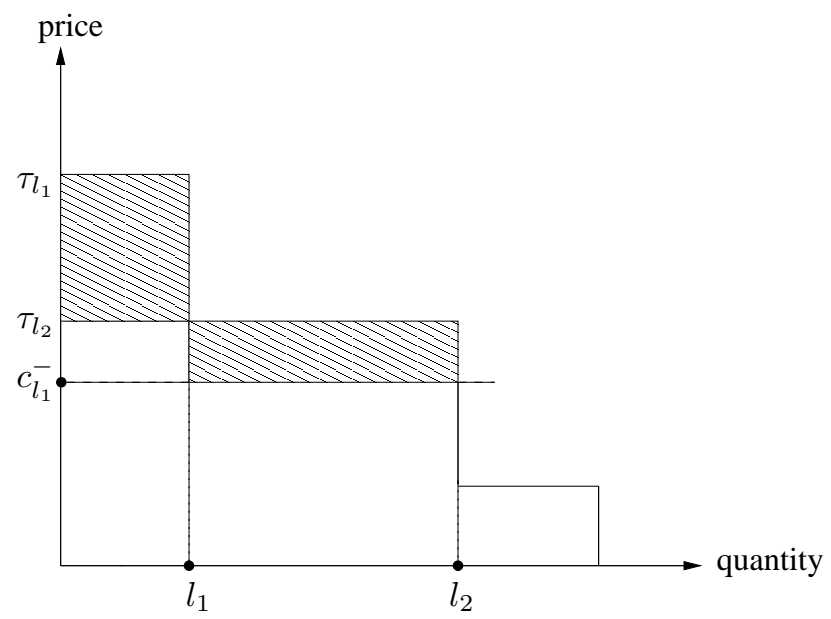

Figure 4: Announced demand curve in the uniform price auction. The two pattern rectangles cover equal areas.

and we obtain

$$
\frac{F\left(\tau_{l_{1}}\right)-F\left(c_{l_{1}}^{-}\right)}{F\left(\tau_{l_{2}}\right)-F\left(c_{l_{1}}^{-}\right)} \geq \frac{l_{2}}{l_{1}} .
$$

The identities

$$
\begin{aligned}
Q_{U}\left(\tau_{l_{1}}, \tau_{l_{2}}, \ldots \tau_{l_{h}}\right)-Q_{U} & \left(\tau_{l_{2}}, \tau_{l_{2}}, \ldots \tau_{l_{h}}\right) \\
& =l_{1}\left[F\left(\tau_{l_{1}}\right)-F\left(\tau_{l_{2}}\right)\right]-\left(l_{2}-l_{1}\right)\left[F\left(\tau_{l_{2}}\right)-F\left(c_{l_{1}}^{-}\right)\right] \\
& =l_{1}\left[F\left(\tau_{l_{1}}\right)-F\left(c_{l_{1}}^{-}\right)\right]-l_{2}\left[F\left(\tau_{l_{2}}\right)-F\left(c_{l_{1}}^{-}\right)\right] \geq 0
\end{aligned}
$$

prove (3.5). The above argument can be applied iteratively $(h-1)$ times to verify the inequality

$$
Q_{U}\left(\tau_{l_{1}}, \tau_{l_{2}}, \ldots \tau_{l_{h}}\right) \geq Q_{U}\left(\tau_{l_{h}}, \tau_{l_{h}}, \ldots \tau_{l_{h}}\right) .
$$

Now one can easily prove $\left(E_{n}\right)$ by applying Theorem 6:

$$
\begin{aligned}
\mathfrak{Q}_{U}\left(\boldsymbol{\sigma}_{U}^{*}\right) & =\int Q_{U}(\mathbf{x}) \mathrm{d} \boldsymbol{\sigma}_{U}^{*}(\mathbf{x}) \geq \int Q_{U}\left(\tau_{h}, \tau_{h}, \ldots \tau_{h}\right) \mathrm{d} \boldsymbol{\sigma}_{U}^{*}(\mathbf{x}) \\
& >\int Q_{U}\left(z_{D}, z_{D}, \ldots z_{D}\right) \mathrm{d} \boldsymbol{\sigma}_{U}^{*}(\mathbf{x})=n \cdot F\left(z_{D}\right) \\
& =\int Q_{D}\left(z_{D}, z_{D}, \ldots z_{D}\right) \mathrm{d} \boldsymbol{\sigma}_{D}^{*}(\mathbf{x})=\mathfrak{Q}_{D}\left(\boldsymbol{\sigma}_{D}^{*}\right) .
\end{aligned}
$$

The proof of $\left(E_{2}\right)$ is analogous (apply Theorem 4 ). 


\section{A numerical example}

We consider the following two bidder example: $v=1$ and the marginal cost of the auctioneer is uniformly distributed: $f(c)=1$ for $c \in[0,1]$.

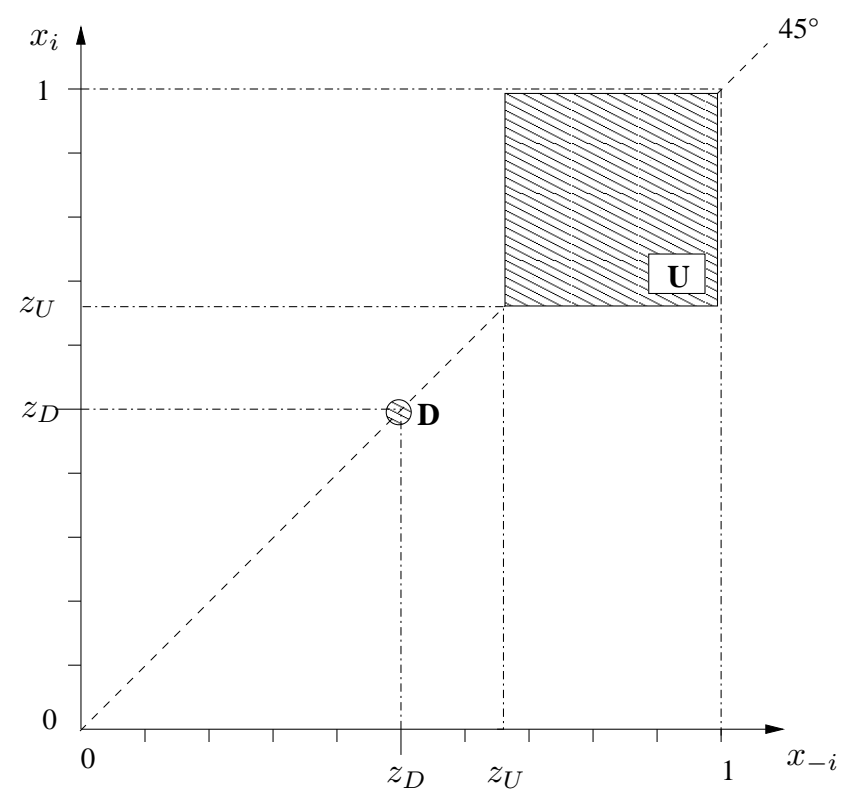

Figure 5: Numerical example: $v=1, n=2$ and $f(c)=1$ for $c \in[0,1]$. The supports of the rationalizable strategy sets in the two auction forms (the pattern areas) are disjoint. Bids in the uniform price auction are higher with a probability of one.

In the discriminatory auction the two bidders bid $z_{D}=\frac{1}{2}$ with a probability of one. This is their only rationalizable strategy. The support of all rationalizable strategies in the uniform price auction lies in the interval

$$
\left[z_{U}, v\right]=\left[\frac{2}{3}, 1\right]
$$

This is illustrated in Figure 5. The average trade quantities of the discriminatory auction and the uniform price auctions are

$$
\mathfrak{Q}_{D}=\int_{0}^{\frac{1}{2}} 2 \mathrm{~d} c=1, \quad \mathfrak{Q}_{U}>\frac{4}{3}
$$


Seller's revenue is clearly higher in the uniform price auction. The payoff of bidder $i$ in the uniform price auction is

$$
R_{i}^{\mathrm{U}}\left(x_{i}, x_{-i}\right)= \begin{cases}\left(1-x_{i}\right) x_{i} & \text { for } x_{i}>2 x_{-i} \\ \left(1-x_{i}\right)\left(2 x_{i}-2 x_{-i}\right)+\left(1-x_{-i}\right)\left(2 x_{-i}-x_{i}\right) & \text { for } 2 x_{-i} \geq x_{i} \geq x_{-i} \\ \left(1-x_{i}\right)\left(2 x_{i}-x_{-i}\right) & \text { for } \frac{x_{-i}}{2} \leq x_{i}<x_{-i} \\ 0 & \text { for } x_{i}<\frac{x_{-i}}{2}\end{cases}
$$

\section{Discriminatory Auction}

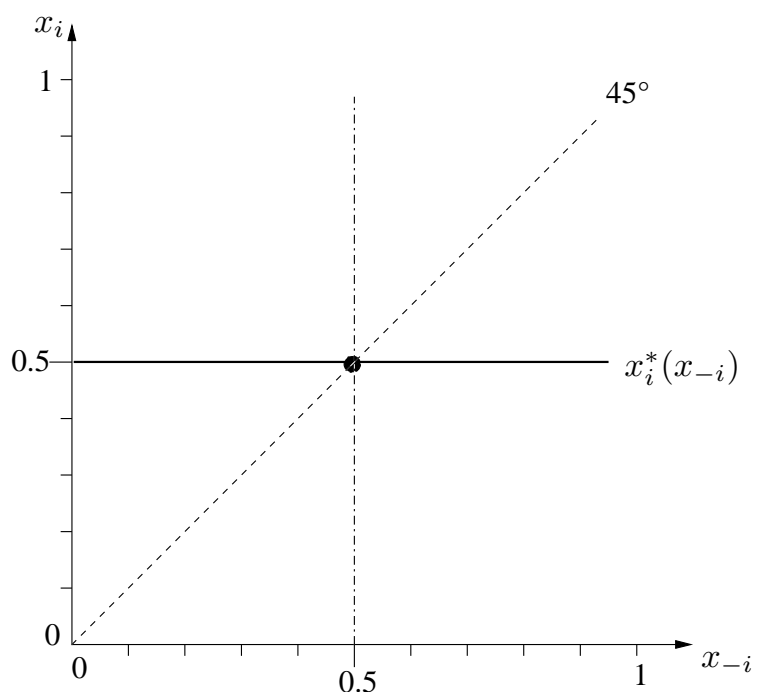

Uniform Price Auction

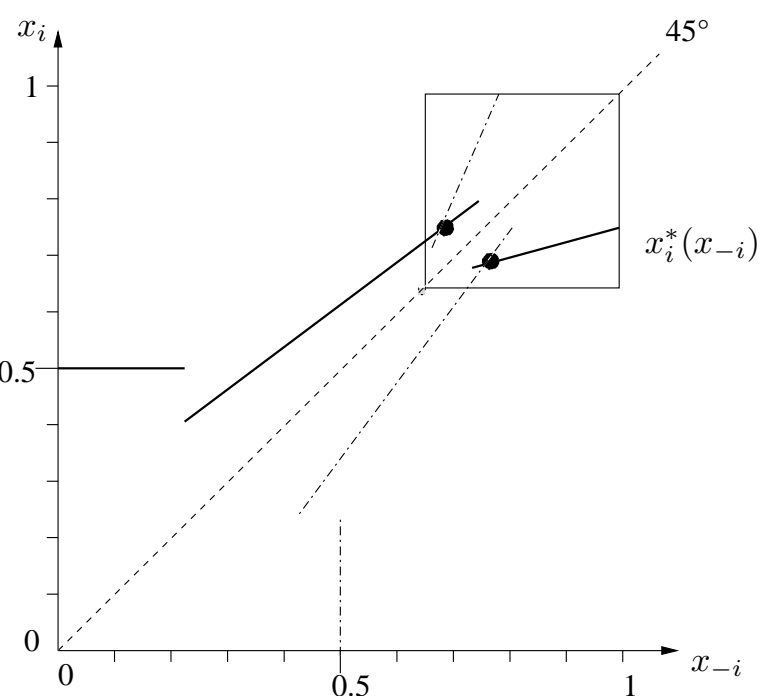

Figure 6: Best responses and pure strategy equilibria (the thick dots) in the uniform price and the discriminatory auctions. The support of the rationalizable strategies of the uniform price auction lies within the square as has been proven in Theorem 4 .

For the (pure strategy) best response correspondence of bidder $i$ in the uniform price auction we obtain

$$
x_{i}^{*}\left(x_{-i}\right)= \begin{cases}\frac{1}{2} & \text { for } x_{-i}<\frac{3-\sqrt{2}}{7}, \\ \left\{\frac{16-3 \sqrt{2}}{28}, \frac{1}{2}\right\} & \text { for } x_{-i}=\frac{3-\sqrt{2}}{7}, \\ \frac{3 x_{-i}+1}{4} & \text { for } x_{-i}=\left(\frac{3-\sqrt{2}}{7}, \frac{3}{4}\right), \\ \left\{\frac{11}{16}, \frac{13}{16}\right\} & \text { for } x_{-i}=\frac{3}{4} \\ \frac{x_{-i}+2}{4} & \text { for } x_{-i} \in\left(\frac{3}{4}, 1\right] .\end{cases}
$$

For that numerical example the uniform price auction has two asymmetric subgame per- 
fect equilibria in pure strategies (see Figure 6 for a graphical illustration):

$$
\left(x_{i, U}^{*}, x_{-i, U}^{*}\right)=\left(\frac{10}{13}, \frac{9}{13}\right), i=1,2 .
$$

For the average trade quantity in equilibrium we obtain

$$
\mathfrak{Q}_{U}=\frac{18}{13}>\frac{4}{3}
$$

Seller's revenue is clearly higher in the uniform price auction.

\section{Discussion}

This paper presents a highly stylized model of competitive bidding in which the seller controls supply ex post. The main result is that the endogenous supply decision, combined with uncertainty about seller's marginal cost, creates a greater tendency for bids to rise in the uniform price auction than in the discriminatory auction. To what extent does this tendency apply to more general settings?

Key element of the comparisons is the assumption that all bidders share the same valuation. This assumption leads to low revenue in the discriminatory auction. Intuitively, the purpose of holding a discriminatory auction is the discrimination among bidders. Price discrimination does not materialize here because all bidders bid the same amount. This result is robust to small differences in the information bidders may have about the common value of the good. As long as bidders' valuations are close, bids will also be close and the discriminatory auction will be inferior from seller's viewpoint. A more significant disparity in the valuations will of course favor the discriminatory auction.

The assumption that bidders demand and can acquire only one unit does not seem to be significant on its own. If a bidder desires several units and values each of these units equally, then bids in the discriminatory auction will be the same as in the single-unit case. This holds true because the payoff of each bidder does not depend on the bids of the other bidders. We can show also for the uniform price auction that, if a bidder can bid for more than one unit, and values all units equally, then he will submit equal bids for all desired units. Different results are obtained when demand is downward sloping. In the discriminatory auction, for instance, bidders will not bid the same price for each unit. Such a scenario is analyzed in Nautz (1995) and Nautz and Wolfstetter (1997), however in these models price is not determined endogenously.

Higher bids in the uniform price auction result from the interplay of two factors uncertainty about marginal cost and seller's profit maximizing decision. Without uncertainty it is easy to see that in the two auctions all bidders will submit bids equal to the 
marginal cost. Seller's profit accrues from bidders' uncertainty in both the uniform price and the discriminatory auction. Uncertainty is more beneficial to the seller in the uniform price auction format because of seller's profit-maximizing behavior. This result might be an important guide for empirical studies.

What is the role of the constant marginal cost assumption in the analysis? If marginal cost were increasing, in the discriminatory auction the seller would generally want to service only a subset of the bidders. In this case bidders' decisions in the discriminatory auction would no longer be independent of other bidders' behavior, and there would be competition among bidders. How equilibria would look like would depend on the way the uncertainty is modelled. The basic intuition seems to carry over: raising a bid raises the winning chances in the two auctions in a similar way, but is more costly in the discriminatory auction. This informal argument favors uniform pricing. Providing equilibrium existence results and obtaining closed form solutions for equilibrium bids does not seem to be feasible and contains a host of new problems. As pointed out in Lengwiler (1999), this makes the assumption of elastic supply analytically attractive. In a recent contribution, LiCalzi and Pavan (2005) show that the seller can raise his revenues in the uniform price auction by committing to an increasing supply schedule. The decision on supply in this model, however, is not dependent on the bids.

Our analysis focused on the uniform price and the discriminatory auctions, but can the seller learn bidders' value by having them cross-report? If a voluntary report of the value of other bidders has no consequences for the payoff of the reporting bidder, then there is no guarantee that bidders will report truthfully. Bidders can coordinate on collectively reporting a value which is much lower than $v$, and this will be an equilibrium. And even if they fail to report the same value, the most unfavorable consequence for them is limited to the situation in which they do not obtain an item. It can also be questioned whether the seller can really commit not to serve individual bidders if this lowers his profits. So, the seller's potential to extract information by cross-reporting does not seem that great in such a variable supply setting.

\section{Conclusion}

The standard pricing techniques, the uniform pricing rule and the price discrimination rule, are widely used by monopolists for the simultaneous sale of multiple units. When a monopolist lacks information about demand, these pricing techniques often take the form of an auction, in which the seller first collects bids from prospective customers and then decides on a supply quantity so as to maximize profit. These auction forms, called variable supply multi-unit auctions, are used on various markets ranging from Treasury bills and IPOs to emission permits and electricity. They differ from the fixed supply 
multi-unit auctions in the sense that the seller participates in the price-setting process as he controls the supply after the bidding. We modelled this scenario as a two-stage game and compared these variable supply pricing mechanisms. We found that due to the uncertainty about supply in a symmetric equilibrium the bidders bid higher in the uniform price auction than in the discriminatory auction. This finding further implies that the uniform price auction is more profitable for the seller and leads to higher average trade volume.

The following intuition helps explain our results. In the discriminatory auction, the winning probability of each bidder is not affected by the bids of his fellow bidders, as the seller optimally serves every bid above his marginal cost. Since the bidders share the same valuation, they submit equal bids. Thus, as in Lengwiler (1999), the right of the seller to discriminate among bidders and charge different prices has no bite. Bidders in the discriminatory auction do not compete at all; in the reduced form of the game a bidder's expected payoff is independent of how other bidders bid. In the uniform price auction, on the other hand, the probability of winning as well as the final price depend on all bids. Submitting higher bids in this auction format proves to be profitable as it raises the probability of winning, but not necessarily the price a bidder has to pay. This simple observation is employed to demonstrate that the uniform price auction induces a more competitive environment and leads to higher equilibrium bids for any number of bidders (see Theorems 4 and 6). Our results are derived without the need to compute the equilibria precisely. Rather, we exploited the properties of the bidders' payoff functions and the equilibrium and rationalizability concepts.

\section{Acknowledgments}

We would like to thank Jürgen Eichberger, Switgard Feuerstein, Hans Gersbach, Hartmut Kogelschatz, and Jörg Oechssler for their guidance and support. We are indebted to Hans Haller for insightful discussions at an early stage of the project. Thank also go to Roberto Burguet, Angel Hernando-Veciana, Wolfgang Leininger and Mike Shor for valuable suggestions. We are grateful for the comments of participants at the 59th European Meeting of the Econometric Society, Madrid (2004), the 9th Spring Meeting of Young Economists, Warsaw (2004), the 2004 Annual Congress of the Verein für Socialpolitik in Dresden, the 2005 Econometric Society North American Winter Meeting in Philadelphia, the 2007 Meeting of the Society for the Advancement in Economic Theory in Kos, and research seminars at the universities of Dortmund and Heidelberg. 


\section{A Appendix}

Proof of property (v) of Theorem 2: There exists $\delta>0$ such that

$$
\partial_{i} R_{i}^{\mathrm{U}}\left(x_{i}, x_{-i}\right)>0 \quad \text { for } \quad x_{-i}<x_{i}<\min \left\{x_{-i}+\delta, z_{U}\right\}
$$

On the set $K:=\left\{\left(y_{i}, y_{-i}\right) \mid 0 \leq y_{-i} \leq z_{U}, 0 \leq y_{i} \leq \frac{v-z_{U}}{2}\right\}$ we define a function $g: K \rightarrow \mathbb{R}$ by

$$
g\left(y_{i}, y_{-i}\right)=\partial_{i} R_{i}^{\mathrm{U}}\left(y_{i}+y_{-i}, y_{-i}\right)
$$

where for $y_{i}=0$ we mean the derivative from above. Notice that we simply expressed the partial derivative as a function of $y_{-i}=x_{-i}$ and the difference $y_{i}=x_{i}-x_{-i}$. The function $g$ is continuous with $g\left(0, y_{-i}\right)>0$ for every $y_{-i} \in\left[0 ; z_{U}\right]$, so the set $H:=g^{-1}((0 ; \infty))$ of points where the partial derivative is strictly positive is open ${ }^{12}$ in $K$ with $\{0\} \times\left[0, z_{U}\right] \subseteq H$. Therefore, as $\left[0, z_{U}\right]$ is compact, there exists ${ }^{13}$ a neighborhood $[0, \delta], \delta>0$, of 0 in $\left[0, \frac{v-z_{U}}{2}\right]$ with $[0 ; \delta] \times\left[0, z_{U}\right] \subseteq H$.

\section{Proof of Theorem 4:}

Part 1: Bidders do not bid higher than their valuation if they play rationalizable strategies:

$$
\sigma((v, m])=0 \quad \text { for all } \quad \sigma \in \Sigma^{U}
$$

For each $\sigma \in \Sigma$, define $\hat{\sigma} \in \Sigma$ by

$$
\hat{\sigma}(B)=\sigma(B \cap[0 ; v])+\sigma((v ; m]) \cdot \mathbb{1}_{v \in B} \text { for } B \in \mathscr{B}
$$

which means, a bidder with strategy $\hat{\sigma}$ bids $v$ whenever a bidder with strategy $\sigma$ would submit a bid from the interval $(v ; m]$. We first remark that $\hat{\sigma}$ always weakly dominates $\sigma$, as bids above $v$ lead to a strictly negative outcome when served. So a strategy $\sigma_{i}$ of player $i$ with $\sigma_{i}((v ; m])>0$ will never be a best response to a strategy $\sigma_{-i}$ of player $-i$, if player $i$ has to pay more than $v$ with strictly positive probability when the strategy combination $\left(\sigma_{i}, \sigma_{-i}\right)$ is played.

Using this property, we will now show by induction that, with the notation of Definition 2 , for $k=1,2, \ldots$

$$
\sigma_{i} \notin \Sigma_{i}^{\mathrm{U}, k}, \quad i=1,2, \quad \text { if } \sigma_{i}\left(\left(\max \left\{v, 2^{-k} m\right\} ; m\right]\right)>0 .
$$

We start with $k=1$. As the other bid is never greater than $m$, bids from the inter-

\footnotetext{
${ }^{12}$ Here we use the fact that pre-images of open sets under continuous mappings are open, see e.g. Königsberger (2002), p. 16.

${ }^{13}$ This follows from the so called "tube lemma", see e.g. Königsberger (2002), p. 32.
} 
val $\left(\max \left\{v, \frac{m}{2}\right\} ; m\right]$ are served when the marginal cost of the seller is below $v$, which will happen with a strictly positive probability. So, by the introductory remark, if $\sigma_{i}\left(\left(\max \left\{v, \frac{m}{2}\right\} ; m\right]\right)>0, \hat{\sigma}_{i}$ will be strictly better than $\sigma_{i}$, regardless of what $-i$ does.

Now assume that equation (A.1) holds for $k-1$. Bids above $\max \left\{v, 2^{-k} m\right\}$ are served when the other bidder does not submit a bid above $\max \left\{v, 2^{-(k-1)} m\right\}$ and the cost is below $v$, which by induction happens with strictly positive probability if the other bidder plays a strategy from $\Sigma_{-i}^{\mathrm{U}, k-1}$. So, for each strategy $\sigma_{i}$ with $\sigma_{i}\left(\left(\max \left\{v, 2^{-k} m\right\} ; m\right]\right)>0$ the strategy $\widehat{\sigma}_{i}$ will be a strictly better response to any element of $\Sigma_{-i}^{\mathrm{U}, k-1}$, which proves (A.1) for $k$.

Part 2: Bidders do not bid lower than $z_{U}$ if they play rationalizable strategies:

$$
\sigma\left(\left[0, z_{U}\right]\right)=0 \text { for all } \sigma \in \Sigma^{U}
$$

Recall that

$$
I_{k}=[(k-1) \cdot \delta, k \cdot \delta) \quad \text { for } \quad k=1,2, \ldots N ; \quad I_{0}=\emptyset
$$

and let

$$
J_{k}=\bigcup_{l=0}^{k} I_{l}=[0, k \delta)
$$

We will iteratively show that

$$
\Sigma_{i}^{U, k} \subseteq\left\{\sigma_{i} \mid \sigma_{i}\left(J_{k}\right)=0\right\}, \quad \text { for } \quad k=1,2, . ., N ; i=1,2
$$

which is sufficient to prove the Lemma. Observe that (A.2) trivially holds for $k=0$. Assume that it holds for $k-1<N$ for player $-i$. We will show that

$$
\Sigma_{i}^{U, k} \subseteq\left\{\sigma_{i} \mid \sigma_{i}\left(J_{k}\right)=0\right\}
$$

Assume on the contrary

$$
\exists \sigma_{i} \in \Sigma_{i}^{U, k} \quad \text { with } \quad \sigma_{i}\left(I_{k}\right)>0 .
$$

We will now demonstrate that for each $\sigma_{-i} \in \operatorname{conv} \Sigma_{-i}^{U,(k-1)}$ there exists $\hat{\sigma}_{i}$ such that $\mathfrak{R}_{i}^{U}\left(\hat{\sigma}_{i}, \sigma_{-i}\right) \geq \mathfrak{R}_{i}^{U}\left(\sigma_{i}, \sigma_{-i}\right)$. This will pose a contradiction to the above assumption (A.4), namely that $\sigma_{i}$ is a best response to some mixed strategy from the set conv $\Sigma_{-i}^{U,(k-1)}$.

Case 1: $\sigma_{-i}\left(J_{2 k}\right)>0$. 
Consider the strategy $\hat{\sigma}_{i}$ :

$$
\hat{\sigma}_{i}(B)=\sigma_{i}\left(B \cap C I_{k}\right)+\sigma_{i}\left(I_{k}\right) \cdot \mathbb{1}_{k \delta \in B} \quad \text { for } B \in \mathscr{B}
$$

where $\mathrm{C} I_{k}$ is the complement set of $I_{k}\left(\mathrm{C} I_{k} \equiv M \backslash I_{k}\right)$ :

$$
\begin{aligned}
\mathfrak{R}_{i}^{U}\left(\hat{\sigma}_{i}, \sigma_{-i}\right)-\mathfrak{R}_{i}^{U}\left(\sigma_{i}, \sigma_{-i}\right) \\
\quad \geq \int\left(\int R_{i}^{\mathrm{U}}\left(x_{i}, x_{-i}\right) \mathrm{d} \hat{\sigma}_{i}\left(x_{i}\right)-\int R_{i}^{\mathrm{U}}\left(x_{i}, x_{-i}\right) \mathrm{d} \sigma_{i}\left(x_{i}\right)\right) \mathrm{d} \sigma_{-i}\left(x_{-i}\right) \\
\quad=\int\left(R_{i}^{\mathrm{U}}\left(k \delta, x_{-i}\right) \cdot \sigma_{i}\left(I_{k}\right)-\int_{I_{k}} R_{i}^{\mathrm{U}}\left(x_{i}, x_{-i}\right) \mathrm{d} \sigma_{i}\left(x_{i}\right)\right) \mathrm{d} \sigma_{-i}\left(x_{-i}\right) \\
\quad=\iint_{I_{k}}\left(R_{i}^{\mathrm{U}}\left(k \delta, x_{-i}\right)-R_{i}^{\mathrm{U}}\left(x_{i}, x_{-i}\right)\right) \mathrm{d} \sigma_{i}\left(x_{i}\right) \mathrm{d} \sigma_{-i}\left(x_{-i}\right) \\
\quad=\int_{C J_{(k-1)}} \int_{I_{k}}\left(R_{i}^{\mathrm{U}}\left(k \delta, x_{-i}\right)-R_{i}^{\mathrm{U}}\left(x_{i}, x_{-i}\right)\right) \mathrm{d} \sigma_{i}\left(x_{i}\right) \mathrm{d} \sigma_{-i}\left(x_{-i}\right) \\
>0
\end{aligned}
$$

(A.6) follows from (A.5) because we assumed that (A.2) holds for $(k-1)<N$ for player $-i$. Further, from Theorem 2 follows that

$$
\begin{aligned}
& R_{i}^{\mathrm{U}}\left(x_{i}, x_{-i}\right)<R_{i}^{\mathrm{U}}\left(k \delta, x_{-i}\right) \quad \text { if } \quad x_{i} \in I_{k} \quad \text { and } \quad(k-1) \cdot \delta \leq x_{-i}<2 k \delta, \\
& R_{i}^{\mathrm{U}}\left(x_{i}, x_{-i}\right) \leq R_{i}^{\mathrm{U}}\left(k \delta, x_{-i}\right) \quad \text { if } \quad x_{i} \in I_{k} \quad \text { and } \quad(k-1) \cdot \delta \leq x_{-i} .
\end{aligned}
$$

As by assumption $\sigma_{-i}\left(J_{2 k}\right)>0$ the inequality (A.7) is also valid.

Case 2: $\sigma_{-i}\left(J_{2 k}\right)=0$. For the strategy $\hat{\sigma}_{i}$, where

$$
\hat{\sigma}_{i}(B)=\sigma_{i}\left(B \cap C I_{k}\right)+\sigma_{i}\left(I_{k}\right) \cdot \mathbb{1}_{\frac{3 v}{4} \in B} \quad \text { for } B \in \mathscr{B}
$$

one observes that

$$
\begin{aligned}
\mathfrak{R}_{i}^{U}\left(\hat{\sigma}_{i}, \sigma_{-i}\right) & -\mathfrak{R}_{i}^{U}\left(\sigma_{i}, \sigma_{-i}\right) \\
& =\int_{\mathrm{CJ}_{2 k}} \int_{I_{k}}\left(R_{i}^{\mathrm{U}}\left(\frac{3 v}{4}, x_{-i}\right)-R_{i}^{\mathrm{U}}\left(x_{i}, x_{-i}\right)\right) \mathrm{d} \sigma_{i}\left(x_{i}\right) \mathrm{d} \sigma_{-i}\left(x_{-i}\right) \\
& =\int_{\mathrm{C} J_{2 k}} \int_{I_{k}}\left(R_{i}^{\mathrm{U}}\left(\frac{3 v}{4}, x_{-i}\right)\right) \mathrm{d} \sigma_{i}\left(x_{i}\right) \mathrm{d} \sigma_{-i}\left(x_{-i}\right)>0 .
\end{aligned}
$$

The inequality (A.8) holds because $R_{i}^{\mathrm{U}}\left(\frac{3 v}{4}, x_{-i}\right)>0$ for $x_{-i} \in[0, v]$.

Proof of Lemma 1: $R_{i}^{\mathrm{U}}(\mathrm{x})$ is continuous in $\mathbf{x}$.

Let $\mathbf{x}$ be an arbitrary bid vector. We will show that for any sequence of bid vectors $\mathbf{x}^{(k)}, k=1,2, \ldots$, with $\mathbf{x}^{(k)} \rightarrow \mathbf{x}$ we have $R_{i}^{\mathrm{U}}\left(\mathbf{x}^{(k)}\right) \rightarrow R_{i}^{\mathrm{U}}(\mathbf{x})$. Using the (easy to prove) 
inequality

$$
\left|a^{\prime} b^{\prime} c^{\prime}-a b c\right| \leq\left|a^{\prime}-a\right| \cdot b^{\prime} c^{\prime}+a \cdot\left|b^{\prime}-b\right| \cdot c^{\prime}+a b \cdot\left|c^{\prime}-c\right|
$$

which holds for arbitrary nonnegative reals $a, b, c, a^{\prime}, b^{\prime}, c^{\prime}$, we obtain

$$
\begin{aligned}
& \left|R_{i}^{\mathrm{U}}\left(\mathbf{x}^{(k)}\right)-R_{i}^{\mathrm{U}}(\mathbf{x})\right| \\
& \left.\leq \sum_{q=0}^{n}\left|\tau_{q}\left(\mathbf{x}^{(k)}\right)-\tau_{q}(\mathbf{x})\right| \cdot P\left(q ; \mathbf{x}^{(k)}\right) \cdot \mathbb{1}_{\left\{\varphi_{\mathbf{x}}(k)\right.}(i) \leq q\right\} \\
& \left.\quad+\sum_{q=0}^{n}\left(v-\tau_{q}(\mathbf{x})\right) \cdot\left|P\left(q ; \mathbf{x}^{(k)}\right)-P(q ; \mathbf{x})\right| \cdot \mathbb{1}_{\left\{\varphi_{\mathbf{x}}(k)\right.}(i) \leq q\right\} \\
& \quad+\sum_{q=0}^{n}\left(v-\tau_{q}(\mathbf{x})\right) \cdot P(q ; \mathbf{x}) \cdot\left|\mathbb{1}_{\left\{\varphi_{\mathbf{x}^{(k)}}(i) \leq q\right\}}-\mathbb{1}_{\left\{\varphi_{\mathbf{x}}(i) \leq q\right\}}\right| .
\end{aligned}
$$

This inequality can be interpreted as a decomposition of the change in expected payoff of bidder $i$ into a price effect, a quantity effect and an allocation effect. As sums, differences, products, quotients, minimums and maximums of continuous functions are continuous, so are the functions $c_{q}^{-}(\cdot), c_{q}^{+}(\cdot), P(q ; \cdot)$, and therefore

$$
\left|\tau_{q}\left(\mathbf{x}^{(k)}\right)-\tau_{q}(\mathbf{x})\right| \rightarrow 0, \quad\left|P\left(q ; \mathbf{x}^{(k)}\right)-P(q ; \mathbf{x})\right| \rightarrow 0
$$

for $k \rightarrow \infty$, which means price and quantity effect tend to 0 . To complete the proof, we will now show that the allocation effect also tends to 0 . This effect can be expressed as

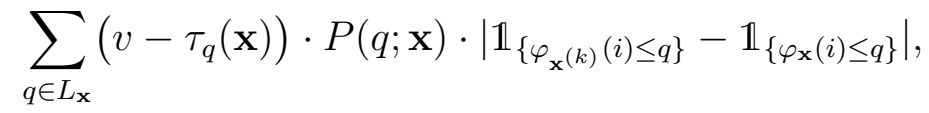

where

$$
L_{\mathbf{x}}=\left\{q \mid \tau_{q}(\mathbf{x})>\tau_{q+1}(\mathbf{x})\right\}
$$

because $P(q ; \mathbf{x})=0$ for $q \notin L_{\mathbf{x}} \cdot{ }^{14}$ In words, one needs to sum only over the positions in the announced demand curve for which an increase in quantity leads to a decrease in the stopout price. This holds true because if several bids are equal, the seller serves with a probability of one either none or all of them. Observe now that there exists $k_{0}$, such that for all $k \geq k_{0}$ we have:

$$
x_{j}^{(k)}<x_{i}^{(k)} \text { if } x_{j}<x_{i} \text { and } x_{j}^{(k)}>x_{i}^{(k)} \text { if } x_{j}>x_{i} \text { for all } i, j \in\{1, \ldots, n\} .
$$

Then the inequalities

$$
\varphi_{\mathbf{x}}(i) \leq q \quad \text { and } \quad \varphi_{\mathbf{x}^{(k)}}(i) \leq q
$$

\footnotetext{
${ }^{14}$ One observes that $c_{q}^{-}=\tau_{q}$ and $c_{q}^{+} \leq \tau_{q}$. Hence $P(q ; \mathbf{x})=0$.
} 
are equivalent for $q \in L_{\mathbf{x}}$ and $k \geq k_{0}$, which completes the proof.

\section{B Appendix}

In this Appendix we prove Theorem 6: in every symmetric mixed strategy equilibrium of the uniform price auction buyers bid with probability one higher than $z_{\mathrm{D}}$ (the equilibrium bid in the discriminatory auction). First we provide some auxiliary statements in the form of several Lemmas.

Lemma 2. Let $\mathcal{L}\left(\mathbf{x}_{-i}\right):=\left[0 ; \min \left(\left\{x_{j} \mid j \neq i\right\} \cup\left\{z_{\mathrm{D}}\right\}\right)\right)$.

(i) For any $i$ and any given $\mathbf{x}_{-i}$, the partial derivative $\partial_{i} R_{i}\left(x_{i} ; \mathbf{x}_{-i}\right)$ exists in all but finitely many points $x_{i} \in \mathcal{L}\left(\mathbf{x}_{-i}\right)$.

(ii) The partial derivative of the bidder that submitted the lowest bid is nonnegative if that bidder submitted a bid not higher than $z_{\mathrm{D}}$. Formally, for any $\mathbf{x}_{-i}$

$$
\partial_{i} R_{i}^{\mathrm{U}}\left(x_{i} ; \mathbf{x}_{-i}\right) \geq 0
$$

for all $x_{i} \in \mathcal{L}\left(\mathbf{x}_{-i}\right)$ for which $\partial_{i} R_{i}^{\mathrm{U}}$ exists.

(iii) The partial derivative of the bidder that submitted the lowest bid is uniformly bounded away from 0 if that bidder submitted a bid not higher than $z_{\mathrm{D}}$ and is served with positive probability. Formally, there exists $\bar{\partial}>0$ such that for any $\mathbf{x}_{-i}$

$$
\partial_{i} R_{i}^{\mathrm{U}}\left(x_{i} ; \mathbf{x}_{-i}\right)>\bar{\partial}
$$

for all $x_{i} \in \mathcal{L}\left(\mathbf{x}_{-i}\right)$ for which $\partial_{i} R_{i}^{\mathrm{U}}$ exists and $c_{i}^{+}\left(x_{i} ; \mathbf{x}_{-i}\right)>0$.

Proof. (i) The expected payoff of bidder $i$ is given by

$$
R_{i}^{\mathrm{U}}(\mathbf{x})=\left(v-x_{i}\right) F\left(c_{n}^{+}(\mathbf{x})\right) .
$$

As, by assumption, $F$ is differentiable, we only have to show the differentiability of $c_{n}^{+}$. Observe that

$$
c_{n}^{+}(\mathbf{x})=\min _{0 \leq q<n} \frac{q \tau_{q}(\mathbf{x})-n x_{i}}{q-n}
$$

and define

$$
\hat{q}\left(x_{i} ; \mathbf{x}_{-i}\right):=\min \underset{0 \leq q<n}{\arg \min } \frac{q \tau_{q}(\mathbf{x})-n x_{i}}{q-n}
$$

then

$$
c_{n}^{+}(\mathbf{x})=\frac{\hat{q}(\mathbf{x}) \tau_{\hat{q}(\mathbf{x})}(\mathbf{x})-n x_{i}}{\hat{q}(\mathbf{x})-n}
$$


We will now show that $\hat{q}\left(x_{i} ; \mathbf{x}_{-i}\right)$ is almost everywhere differentiable in $x_{i}$ and as a consequence so will be $c_{n}^{+}\left(x_{i} ; \mathbf{x}_{-i}\right)$. Since $\hat{q}\left(x_{i} ; \mathbf{x}_{-i}\right)$, as a function of $x_{i}$, takes only finitely many integer values, monotonicity will be sufficient for it to be piecewise constant and therefore differentiable in all but finitely many points. So, to complete the proof, we will show that $\hat{q}\left(x_{i} ; \mathbf{x}_{-i}\right)$ is weakly decreasing in $x_{i}$. Take $x_{i}^{\prime}, x_{i}^{\prime \prime}$ with $x_{i}^{\prime}<x_{i}^{\prime \prime}$, let $q^{\prime}:=\hat{q}\left(x_{i}^{\prime} ; \mathbf{x}_{-i}\right)$ and $q^{\prime \prime}:=\hat{q}\left(x_{i}^{\prime \prime} ; \mathbf{x}_{-i}\right)$, and assume by contradiction that $q^{\prime}<q^{\prime \prime}$. Observe that according to the Definition of $\hat{q}\left(x_{i} ; \mathbf{x}_{-i}\right)$ the quantity $q^{\prime}$ minimizes the quotient

$$
\frac{q \tau_{q}\left(x_{i}^{\prime}, \mathbf{x}_{-i}\right)-n x_{i}^{\prime}}{q-n}
$$

and the quantity $q^{\prime \prime}$ minimizes the quotient

$$
\frac{q \tau_{q}\left(x_{i}^{\prime \prime}, \mathbf{x}_{-i}\right)-n x_{i}^{\prime \prime}}{q-n} .
$$

Considering the inequalities

$$
\begin{aligned}
& \frac{q^{\prime \prime} \tau_{q^{\prime \prime}}\left(x_{i}^{\prime \prime}, \mathbf{x}_{-i}\right)-n x_{i}^{\prime \prime}}{q^{\prime \prime}-n}-\frac{q^{\prime} \tau_{q^{\prime}}\left(x_{i}^{\prime \prime}, \mathbf{x}_{-i}\right)-n x_{i}^{\prime \prime}}{q^{\prime}-n} \\
& \quad=\frac{q^{\prime \prime} \tau_{q^{\prime \prime}}\left(x_{i}^{\prime \prime}, \mathbf{x}_{-i}\right)-n x_{i}^{\prime \prime}}{q^{\prime \prime}-n}-\frac{q^{\prime \prime} \tau_{q^{\prime \prime}}\left(x_{i}^{\prime \prime}, \mathbf{x}_{-i}\right)-n x_{i}^{\prime}}{q^{\prime \prime}-n}+\frac{q^{\prime \prime} \tau_{q^{\prime \prime}}\left(x_{i}^{\prime \prime}, \mathbf{x}_{-i}\right)-n x_{i}^{\prime}}{q^{\prime \prime}-n}-\frac{q^{\prime} \tau_{q^{\prime}}\left(x_{i}^{\prime \prime}, \mathbf{x}_{-i}\right)-n x_{i}^{\prime \prime}}{q^{\prime}-n} \\
& \quad \geq \frac{q^{\prime \prime} \tau_{q^{\prime \prime}}\left(x_{i}^{\prime \prime}, \mathbf{x}_{-i}\right)-n x_{i}^{\prime \prime}}{q^{\prime \prime}-n}-\frac{q^{\prime \prime} \tau_{q^{\prime \prime}}\left(x_{i}^{\prime \prime}, \mathbf{x}_{-i}\right)-n x_{i}^{\prime}}{q^{\prime \prime}-n}+\frac{q^{\prime} \tau_{q^{\prime}}\left(x_{i}^{\prime \prime}, \mathbf{x}_{-i}\right)-n x_{i}^{\prime}}{q^{\prime}-n}-\frac{q^{\prime} \tau_{q^{\prime}}\left(x_{i}^{\prime \prime}, \mathbf{x}_{-i}\right)-n x_{i}^{\prime \prime}}{q^{\prime}-n} \\
& =\frac{n}{n-q^{\prime \prime}}\left(x_{i}^{\prime \prime}-x_{i}^{\prime}\right)-\frac{n}{n-q^{\prime}}\left(x_{i}^{\prime \prime}-x_{i}^{\prime}\right) \\
& >0
\end{aligned}
$$

we reach a contradiction to the statement that $q^{\prime \prime}$ minimizes the quotient

$$
\frac{q \tau_{q}\left(x_{i}^{\prime \prime}, \mathbf{x}_{-i}\right)-n x_{i}^{\prime \prime}}{q-n}
$$

(ii) For all $c_{i}^{+}\left(x_{i} ; \mathbf{x}_{-i}\right) \leq 0$, we have $R_{i}^{\mathrm{U}}\left(x_{i} ; \mathbf{x}_{-i}\right)=0$ and thus $\partial_{i} R_{i}^{\mathrm{U}}\left(x_{i} ; \mathbf{x}_{-i}\right)=0$. For the case $c_{i}^{+}\left(x_{i} ; \mathbf{x}_{-i}\right)>0$ see the next part.

(iii) By assumption there are bids strictly higher than $x_{i}$, therefore $\hat{q}(\mathbf{x}) \geq 1$ and $c_{n}^{+}(\mathbf{x})<$ $x_{i}$. Let $\underline{f}:=\min _{c \in[0, \bar{c}]} f(c)$. As $f$ is continuous and strictly positive in the interval $[0, \bar{c}]$ we have $\underline{f}>0$. Recall also that $F / f$ is increasing by assumption. Because $c_{n}^{+}(\mathbf{x})<x_{i}<z_{\mathrm{D}}$, 
the following (in)equalities are valid for all points in which the partial derivative exists:

$$
\begin{aligned}
\partial_{i} R_{i}^{\mathrm{U}}(\mathbf{x}) & =\left(v-x_{i}\right) \cdot f\left(c_{n}^{+}(\mathbf{x})\right) \cdot \partial_{i} c_{n}^{+}(\mathbf{x})-F\left(c_{n}^{+}(\mathbf{x})\right) \\
& =\left(v-x_{i}\right) \cdot f\left(c_{n}^{+}(\mathbf{x})\right) \cdot \frac{n}{n-\hat{q}(\mathbf{x})}-F\left(c_{n}^{+}(\mathbf{x})\right) \\
& \geq\left(v-x_{i}\right) \cdot f\left(c_{n}^{+}(\mathbf{x})\right) \cdot \frac{n}{n-1}-F\left(c_{n}^{+}(\mathbf{x})\right) \\
& =\frac{n}{n-1} \cdot f\left(c_{n}^{+}(\mathbf{x})\right)\left(v-x_{i}-\frac{n-1}{n} \cdot \frac{F\left(c_{n}^{+}(\mathbf{x})\right)}{f\left(c_{n}^{+}(\mathbf{x})\right)}\right) \\
& >\frac{n}{n-1} \cdot \underline{f} \cdot\left(v-z_{\mathrm{D}}-\frac{n-1}{n} \cdot \frac{F\left(z_{\mathrm{D}}\right)}{f\left(z_{\mathrm{D}}\right)}\right)=: \bar{\partial} .
\end{aligned}
$$

Observe that $\bar{\partial}>0$ because

$$
v-z_{\mathrm{D}}-\frac{n-1}{n} \cdot \frac{F\left(z_{\mathrm{D}}\right)}{f\left(z_{\mathrm{D}}\right)}>v-z_{\mathrm{D}}-\frac{F\left(z_{\mathrm{D}}\right)}{f\left(z_{\mathrm{D}}\right)}=0 .
$$

Lemma 3. For any $\mathbf{x} \in[0, v]^{n}$ and any $\varepsilon>0$ for which $x_{i}+\varepsilon \leq v$ the following inequality holds:

$$
R_{i}\left(x_{i}+\varepsilon ; \mathbf{x}_{-i}\right)-R_{i}\left(x_{i} ; \mathbf{x}_{-i}\right) \geq-1 \cdot \varepsilon
$$

Proof. The inequality applies because an increase in the bid of bidder $i$ can lead to an increase in the stop-out price (with some probability), but does not lower the winning chances of that bidder.

Lemma 4. Let $\mathbf{x}$ be such that there exists $x$ with $x \leq x_{j}<\frac{n}{n-1} \cdot x$ for all $j$. Then $c_{n}^{+}(\mathbf{x})>0$ (that means, the bidder with the lowest bid is served with positive probability). Proof. We have

$$
c_{n}^{+}(\mathbf{x})>\frac{n x-(n-1) \cdot \frac{n}{n-1} \cdot x}{n-n+1}=0 .
$$

Lemma 5. If all bidders except one (say, bidder $i$ ) submit a bid of $x \in[0, v$ ) (that means, $x_{j}=x$ for $j \neq i$ ) then there exist $\varepsilon>0$ and $\widetilde{\partial}>0$ such that for $x_{i} \in[x, x+\varepsilon)$ the following holds: ${ }^{15} \partial_{i} R_{i}^{\mathrm{U}}\left(x_{i}, x, \ldots, x\right)>\widetilde{\partial}$.

Proof. From

$$
R_{i}^{\mathrm{U}}\left(x_{i}, x, \ldots, x\right)=(v-x) \cdot F\left(\frac{n x-x_{i}}{n-1}\right)+\left(v-x_{i}\right) \cdot\left(F\left(x_{i}\right)-F\left(\frac{n x-x_{i}}{n-1}\right)\right)
$$

\footnotetext{
${ }^{15}$ For $x_{i}=x$ we mean the derivative from above.
} 
we obtain the partial derivative function

$$
\begin{array}{r}
\partial_{i} R_{i}^{\mathrm{U}}\left(x_{i}, x, \ldots, x\right)=-\frac{v-x}{n-1} \\
\cdot f\left(\frac{n x-x_{i}}{n-1}\right)-\left(F\left(x_{i}\right)-F\left(\frac{n x-x_{i}}{n-1}\right)\right) \\
+\left(v-x_{i}\right) \cdot\left(f\left(x_{i}\right)+\frac{1}{n-1} f\left(\frac{n x-x_{i}}{n-1}\right)\right),
\end{array}
$$

which is continuous in $x_{i}$. As $\partial_{i} R_{i}^{\mathrm{U}}(x, x, \ldots, x)=(v-x) \cdot f(x)>0$, there exist $\varepsilon>0$ and $\widetilde{\partial}>0$ such that $\partial_{i} R_{i}^{\mathrm{U}}\left(x_{i}, x, \ldots, x\right)>\widetilde{\partial}$ for $x_{i} \in[x, x+\varepsilon)$.

Lemma 6. Let $\mathbf{x}$ be such that there exist bidders $i, j, k$ with $x_{i} \geq x_{k}$ and

$$
x_{j}>x_{k}+(n-1)^{2}\left(x_{i}-x_{k}\right) .
$$

Then

$$
\partial_{i}^{+} R_{i}^{\mathrm{U}}(\mathbf{x})=0 .
$$

Proof. Observe that $\varphi_{\mathbf{x}}(i) \leq(n-1) .{ }^{16}$ We have

$$
c_{\varphi_{\mathbf{x}}(i)}^{+}(\mathbf{x}) \leq \frac{x_{i} \cdot(n-1)-x_{j}}{n-2}, \quad c_{\varphi_{\mathbf{x}}(i)}^{-}(\mathbf{x}) \geq n \cdot x_{k}-(n-1) \cdot x_{i}
$$

The identities

$$
\begin{aligned}
\frac{x_{i} \cdot(n-1)-x_{j}}{n-2} & <n \cdot x_{k}-(n-1) \cdot x_{i} \Leftrightarrow \\
x_{i} \cdot(n-1)-x_{j} & <n \cdot(n-2) \cdot x_{k}-(n-2) \cdot(n-1) \cdot x_{i} \Leftrightarrow \\
x_{j} & >(n-1)^{2} \cdot x_{i}-n \cdot(n-2) \cdot x_{k} \Leftrightarrow \\
x_{j} & >(n-1)^{2} \cdot x_{i}-\left[(n-1)^{2}-1\right] \cdot x_{k} \Leftrightarrow \\
x_{j} & >x_{k}+(n-1)^{2}\left(x_{i}-x_{k}\right),
\end{aligned}
$$

verify that

$$
c_{\varphi_{\mathbf{x}}(i)}^{+}(\mathbf{x})<c_{\varphi_{\mathbf{x}}(i)}^{-}(\mathbf{x}) \text { for } x_{j}>x_{k}+(n-1)^{2}\left(x_{i}-x_{k}\right),
$$

which completes the proof. With these preliminaries we can prove now Theorem 6 .

\section{Proof of Theorem 6.}

Let $\boldsymbol{\sigma}^{*}$ be a symmetric equilibrium, and let $z_{*}=\max \left\{z \mid \sigma_{i}^{*}([z, v])=1\right\}$ be the lower bound of the support of the bidders' strategies in that equilibrium. Assume by contradiction $z_{*} \leq z_{\mathrm{D}}$. Take an arbitrary bidder $i$ and consider a deviation strategy $\sigma_{i}^{\varepsilon}$, which

\footnotetext{
${ }^{16}$ If bidder $i$ submits also a bid of $x_{k}$, we choose $\varphi_{\mathbf{x}}$ so that bidder $i$ obtains a number lower than bidder $k$.
} 
only shifts the probability mass of the small interval $Z_{*}^{\varepsilon}=\left[z_{*}, z_{*}+\varepsilon\right)$ to the point $z_{*}+\varepsilon$ :

$$
\sigma_{i}^{\varepsilon}(B)=\sigma_{i}\left(B \cap C Z_{*}^{\varepsilon}\right)+\sigma_{i}\left(Z_{*}^{\varepsilon}\right) \cdot \mathbb{1}_{\left\{z_{*}+\varepsilon \in B\right\}} \quad \text { for } B \in \mathscr{B}
$$

We will show that, for $\varepsilon$ small enough, this deviation strategy will be more profitable for player $i$, a contradiction to the equilibrium assumption. To show this, we define the intervals

$$
Z:=\left[z_{*}, v\right], \quad Z_{0}^{\varepsilon}:=\left[z_{*}+(n-1)^{2} \varepsilon, \min \left\{v, \frac{n}{n-1} \cdot z_{*}\right\}\right)
$$

and the sets

$$
\begin{gathered}
\mathcal{Z}=Z^{n-1}, \quad \mathcal{Z}^{\varepsilon}=\left(\left\{z_{*}\right\} \cup\left[z_{*}+(n-1)^{2} \varepsilon, v\right]\right)^{n-1}, \\
\mathcal{Z}_{0}^{\varepsilon}=\left(Z_{0}^{\varepsilon}\right)^{n-1}, \quad \mathcal{Z}_{*}=\left\{z_{*}\right\}^{n-1} .
\end{gathered}
$$

Then we break down the set $\mathcal{Z}$ into the following four sets: $\mathcal{Z} \backslash \mathcal{Z}^{\varepsilon}, \mathcal{Z}^{\varepsilon} \backslash\left(\mathcal{Z}_{0}^{\varepsilon} \cup \mathcal{Z}_{*}\right), Z_{0}^{\varepsilon}$ and $\mathcal{Z}_{*}$. In the case of $n=3$ bidders, taken from the perspective of bidder 3 , all these sets are represented in Figure 7. Consider the difference

$$
\begin{aligned}
\mathfrak{R}_{i}^{\mathrm{U}}\left(\sigma_{i}^{\varepsilon}, \boldsymbol{\sigma}_{-i}^{*}\right)-\mathfrak{R}_{i}^{\mathrm{U}}\left(\sigma_{i}^{*}, \boldsymbol{\sigma}_{-i}^{*}\right) & \\
= & \int_{\mathcal{Z} \backslash \mathcal{Z}^{\varepsilon}} \int_{Z_{*}^{\varepsilon}}\left(R_{i}^{\mathrm{U}}\left(z_{*}+\varepsilon, \mathbf{x}_{-i}\right)-R_{i}^{\mathrm{U}}\left(x_{i}, \mathbf{x}_{-i}\right)\right) \mathrm{d} \sigma_{i}^{*}\left(x_{i}\right) \mathrm{d} \boldsymbol{\sigma}_{-i}^{*}\left(\mathbf{x}_{-i}\right) \\
& +\int_{\mathcal{Z}^{\varepsilon} \backslash\left(\mathcal{Z}_{0}^{\varepsilon} \cup \mathcal{Z}_{*}\right)} \int_{Z_{*}^{\varepsilon}}\left(R_{i}^{\mathrm{U}}\left(z_{*}+\varepsilon, \mathbf{x}_{-i}\right)-R_{i}^{\mathrm{U}}\left(x_{i}, \mathbf{x}_{-i}\right)\right) \mathrm{d} \sigma_{i}^{*}\left(x_{i}\right) \mathrm{d} \boldsymbol{\sigma}_{-i}^{*}\left(\mathbf{x}_{-i}\right) \\
& +\int_{\mathcal{Z}_{0}^{\varepsilon}} \int_{Z_{*}^{\varepsilon}}\left(R_{i}^{\mathrm{U}}\left(z_{*}+\varepsilon, \mathbf{x}_{-i}\right)-R_{i}^{\mathrm{U}}\left(x_{i}, \mathbf{x}_{-i}\right)\right) \mathrm{d} \sigma_{i}^{*}\left(x_{i}\right) \mathrm{d} \boldsymbol{\sigma}_{-i}^{*}\left(\mathbf{x}_{-i}\right) \\
& +\int_{\mathcal{Z}_{*}} \int_{Z_{*}^{\varepsilon}}\left(R_{i}^{\mathrm{U}}\left(z_{*}+\varepsilon, \mathbf{x}_{-i}\right)-R_{i}^{\mathrm{U}}\left(x_{i}, \mathbf{x}_{-i}\right)\right) \mathrm{d} \sigma_{i}^{*}\left(x_{i}\right) \mathrm{d} \boldsymbol{\sigma}_{-i}^{*}\left(\mathbf{x}_{-i}\right) .
\end{aligned}
$$

For $\varepsilon>0$ small enough, we obtain lower bounds of the four terms by using Lemma 3 for the first term, Lemmas $2[(\mathrm{i}) \&(\mathrm{ii})]$ and Lemma 6 for the second one, Lemmas 2 [(i)\&(iii)] and Lemma 4 for the third one ${ }^{17}$ and Lemma 5 for the fourth term, which leads us to the following (in)equalities.

\footnotetext{
${ }^{17}$ Lemma 4 guarantees that in the considered set $c_{n}^{+}(\mathbf{x})>0$; lemma 2 ensures the existence of $\bar{\partial}>0$.
} 

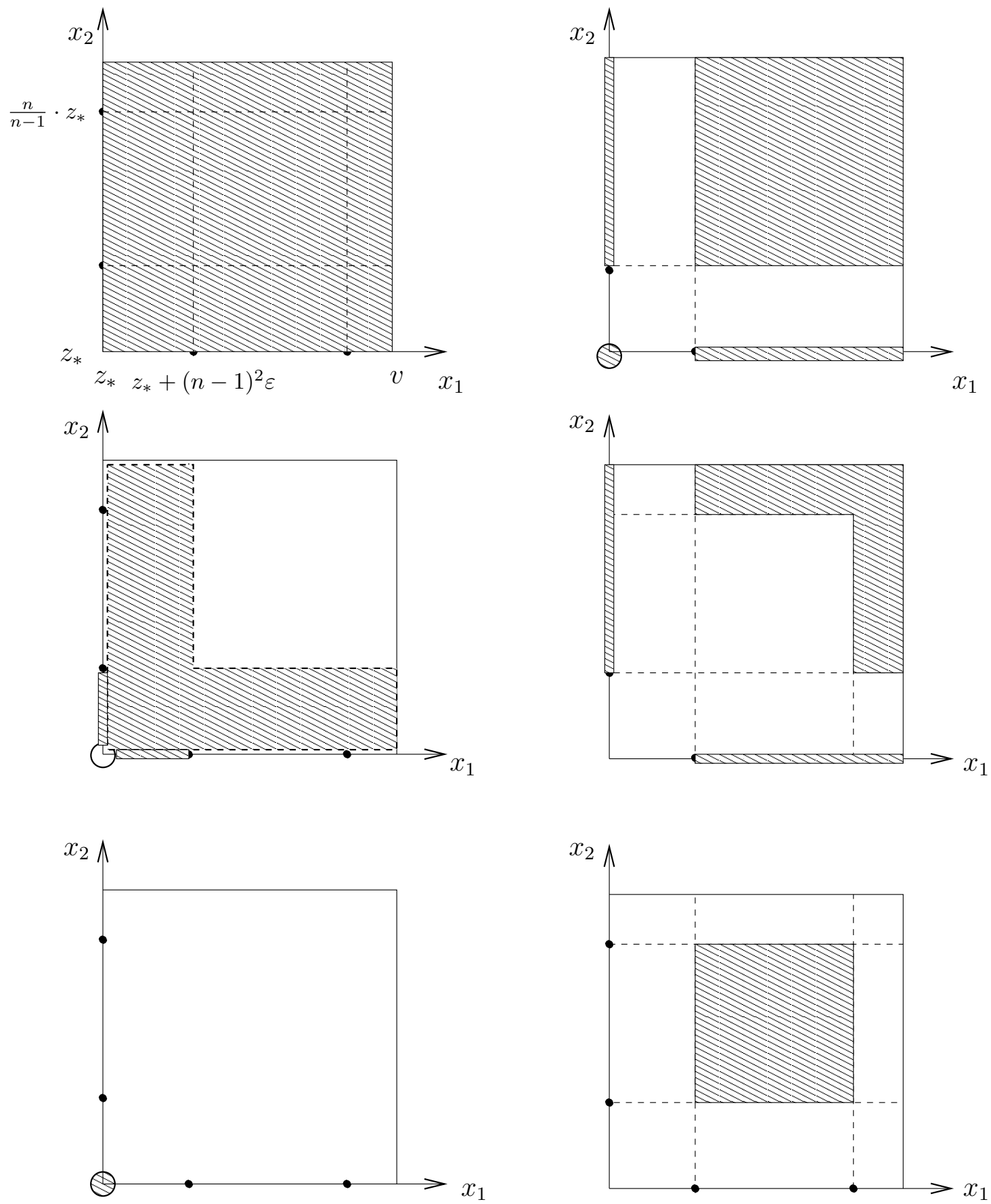

Figure 7: The pattern ares represent the sets $\mathcal{Z}$ (upper-left), $\mathcal{Z}^{\varepsilon}$ (upper-right), $\mathcal{Z} \backslash \mathcal{Z}^{\varepsilon}$ (middleleft), $\mathcal{Z}^{\varepsilon} \backslash\left(\mathcal{Z}_{0}^{\varepsilon} \cup \mathcal{Z}_{*}\right)$ (middle-right), $\mathcal{Z}_{*}$ (lower-left) and $Z_{0}^{\varepsilon}$ (lower-right) for $n=3$ bidders. 


$$
\begin{aligned}
\mathfrak{R}_{i}^{\mathrm{U}}\left(\sigma_{i}^{\varepsilon}, \boldsymbol{\sigma}_{-i}^{*}\right)-\mathfrak{R}_{i}^{\mathrm{U}}\left(\sigma_{i}^{*}, \boldsymbol{\sigma}_{-i}^{*}\right) \\
\geq \int_{\mathcal{Z} \backslash \mathcal{Z}^{\varepsilon}} \int_{Z_{*}^{\varepsilon}}(-1) \cdot\left(z_{*}+\varepsilon-x_{i}\right) \mathrm{d} \sigma_{i}^{*}\left(x_{i}\right) \mathrm{d} \boldsymbol{\sigma}_{-i}^{*}\left(\mathbf{x}_{-i}\right) \\
\quad+\int_{\mathcal{Z}^{\varepsilon} \backslash\left(\mathcal{Z}_{0}^{\varepsilon} \cup \mathcal{Z}_{*}\right)} \int_{Z_{*}^{\varepsilon}} 0 \cdot\left(z_{*}+\varepsilon-x_{i}\right) \mathrm{d} \sigma_{i}^{*}\left(x_{i}\right) \mathrm{d} \boldsymbol{\sigma}_{-i}^{*}\left(\mathbf{x}_{-i}\right) \\
\quad+\int_{\mathcal{Z}_{0}^{\varepsilon}} \int_{Z_{*}^{\varepsilon}} \bar{\partial} \cdot\left(z_{*}+\varepsilon-x_{i}\right) \mathrm{d} \sigma_{i}^{*}\left(x_{i}\right) \mathrm{d} \boldsymbol{\sigma}_{-i}^{*}\left(\mathbf{x}_{-i}\right) \\
\quad+\int_{\mathcal{Z}_{*}} \int_{Z_{*}^{\varepsilon}} \tilde{\partial} \cdot \varepsilon \mathrm{d} \sigma_{i}^{*}\left(x_{i}\right) \mathrm{d} \boldsymbol{\sigma}_{-i}^{*}\left(\mathbf{x}_{-i}\right) \\
=\int_{Z_{*}^{\varepsilon}}\left(z_{*}+\varepsilon-x_{i}\right) \mathrm{d} \sigma_{i}^{*}\left(x_{i}\right) \cdot\left((-1) \cdot \boldsymbol{\sigma}_{-i}^{*}\left(\mathcal{Z} \backslash \mathcal{Z}^{\varepsilon}\right)+\bar{\partial} \cdot \boldsymbol{\sigma}_{-i}^{*}\left(\mathcal{Z}_{0}^{\varepsilon}\right)\right)+\tilde{\partial} \varepsilon \boldsymbol{\sigma}_{-i}^{*}\left(\mathcal{Z}_{*}\right) .
\end{aligned}
$$

We will prove that for sufficiently small $\varepsilon>0$ the expression in the last line is positive. To begin with, observe that $\lim _{\varepsilon \rightarrow 0} \boldsymbol{\sigma}_{-i}^{*}\left(\mathcal{Z} \backslash \mathcal{Z}^{\varepsilon}\right)=0$. So, if there exists an $\varepsilon>0$ for which $\boldsymbol{\sigma}_{-i}^{*}\left(\mathcal{Z}_{0}^{\varepsilon}\right)>0$, then $\lim _{\varepsilon \rightarrow 0} \boldsymbol{\sigma}_{-i}^{*}\left(\mathcal{Z}_{0}^{\varepsilon}\right)>0$. Consequently, $\lim _{\varepsilon \rightarrow 0}\left((-1) \cdot \boldsymbol{\sigma}_{-i}^{*}\left(\mathcal{Z} \backslash \mathcal{Z}^{\varepsilon}\right)+\bar{\partial}\right.$. $\left.\boldsymbol{\sigma}_{-i}^{*}\left(\mathcal{Z}_{0}^{\varepsilon}\right)\right)>0$. If, on the other hand, $\boldsymbol{\sigma}_{-i}^{*}\left(\mathcal{Z}_{0}^{\varepsilon}\right)=0$ for all $\varepsilon>0$, then $\boldsymbol{\sigma}_{-i}^{*}\left(\mathcal{Z} \backslash \mathcal{Z}^{\varepsilon}\right)=0$ and $(-1) \cdot \boldsymbol{\sigma}_{-i}^{*}\left(\mathcal{Z} \backslash \mathcal{Z}^{\varepsilon}\right)+\bar{\partial} \cdot \boldsymbol{\sigma}_{-i}^{*}\left(\mathcal{Z}_{0}^{\varepsilon}\right)=0$ for all $\varepsilon>0$. In this case $\boldsymbol{\sigma}_{-i}^{*}\left(\mathcal{Z}_{*}\right)>0$, because $z_{*}$ was assumed to be the lower bound of the symmetric equilibrium mixed strategy. In either case we can state the existence of an $\varepsilon>0$ for which the expression in the last line is positive and consequently $\mathfrak{R}_{i}^{\mathrm{U}}\left(\sigma_{i}^{\varepsilon}, \boldsymbol{\sigma}_{-i}^{*}\right)-\mathfrak{R}_{i}^{\mathrm{U}}\left(\sigma_{i}^{*}, \boldsymbol{\sigma}_{-i}^{*}\right)>0$, which completes the proof.

\section{References}

Back, K. and J. F. Zender (1993), "Auctions of Divisible Goods: on the Rationale of the Treasury Experiment", Review of Financial Studies 6, 733-764.

Back, K. and J. F. Zender (2001), "Auctions of Divisible Goods with Endogenous Supply", Economics Letters 73, 29-34.

Bagnoli, M. and T. Bergstrom (2005), "Log-concave probability and its applications", Economic Theory 26, 445-469.

Becker, J. G. and D. S. Damianov (2006), "On the Existence of Symmetric Mixed Strategy Equilibria", Economic Letters 90, 84-87.

Bernheim, B. D. (1984), "Rationalizable Strategic Behavior", Econometrica 52, 10071028.

Bjonnes, G. H. (2001), Bidder Behavior in Uniform Price Auctions: Evidence from Norwegian Treasury Bond Auctions, Working paper, Norwegian School of Management. 
Fudenberg, D. and J. Tirole (1991), Game Theory, MIT Press, Cambridge, Massachusetts.

Glicksberg, I. L. (1952), "A Further Generalization of the Kakutani Fixed Point Theorem, With Application to Nash Equilibrium Points", Proceedings of the American Mathematical Society 3, 170-174.

Goldreich, D. (2007), "Underpricing in Discriminatory and Uniform-Price Treasury Auctions", Journal of Financial and Quantitative Analysis 42, 443-466.

Heller, D. and Y. Lengwiler (2001), "Should the Treasury Price Discriminate? A Procedure for Computing Hypothetical Bid Functions", Journal of Institutional and Theoretical Economics 157, 413-429.

Keloharju, M., K. G. Nyborg and K. Rydqvist (2005), "Strategic Behavior and Underpricing in Uniform Price Auctions: Evidence from Finnish Treasury Auctions", Journal of Finance 60, 1865-1902.

Königsberger, K. (2002), Analysis 2, 4th edn, Springer, Berlin, Heidelberg, New York.

Kremer, I. and K. Nyborg (2004), "Divisible-Good Auctions: the Role of Allocation Rules", RAND Journal of Economics 35, 147-159.

Lengwiler, Y. (1999), "The Multiple Unit Auction with Variable Supply", Economic Theory $14,373-392$.

LiCalzi, M. and A. Pavan (2005), "Tilting the Supply Schedule to Enhance Competition in Uniform Price Auctions", European Economic Review 49, 227-250.

Malvey, P. F. and C. M. Archibald (1998), Uniform Price Auctions: Update of the U.S. Treasury Experience, Manuscript, Office of Market Finance, U.S. Treasury, Washington, D.C. 20220.

McAdams, D. (2007), "Adjustable Supply in Uniform Price Auctions: Non-Commitment as a Strategic Tool", Economics Letters 95, 48-53.

Milgrom, P. and R. Weber (1982), "A Theory of Auctions and Competitive Bidding", Econometrica 50, 1089-1122.

Nautz, D. (1995), "Optimal Bidding in Multi-Unit Auctions With Many Bidders", Economics Letters 48, 301-306.

Nautz, D. and E. Wolfstetter (1997), "Bid Shading and Risk Aversion in Multi-Unit Auctions with Many Bidders", Economics Letters 56, 195-200. 
Nyborg, K. and I. Strebulaev (2004), "Multiple Unit Auctions and Short Squeezes", Review of Financial Studies, 17, 545-580.

Nyborg, K., K. Rydqvist and S. Sundaresan (2002), "Bidder Behavior in Multi-Unit Auctions: Evidence from Swedish Treasury Auctions", Journal of Political Economy 110, 394-424.

Pearce, D. G. (1984), "Rationalizable Strategic Behavior and the Problem of Perfection", Econometrica 52, 1029-1050.

Rocholl, J. (2004), Discriminatory Auctions with Seller Discretion: Evidence from German Treasury Auctions, Working paper, Kenan-Flagler Business School, University of North Carolina at Chapel Hill.

Scalia, A. (1997), Bidder Profitability under Uniform Price Auctions and Systematic Reopenings: the Case of Italian Treasury Bonds, Working paper, Bank of Italy.

Umlauf, S. R. (1993), "An Empirical Study of the Mexican T-bill Auction", Journal of Financial Economics 33, 313-340.

Wang, J. and J. F. Zender (2002), "Auctioning Divisible Goods", Economic Theory 19, 673-705.

Wilson, R. (1979), "Auctions of Shares", Quarterly Journal of Economics 93, 675-698. 


\section{Working Papers of the Center of Economic Research at ETH Zurich}

(PDF-files of the Working Papers can be downloaded at www.cer.ethz.ch/research).

08/80 D. S. Damianov and J. G. Becker Auctions with Variable Supply: Uniform Price versus Discriminatory

08/79 H. Gersbach, M. T. Schneider and O. Schneller On the Design of Basic-Research Policy

08/78 C. N. Brunnschweiler and E. H. Bulte Natural Resources and Violent Conflict: Resource Abundance, Dependence and the Onset of Civil Wars

07/77 A. Schäfer, S. Valente Habit Formation, Dynastic Altruism, and Population Dynamics

07/76 R. Winkler Why do ICDPs fail? The relationship between subsistence farming, poaching and ecotourism in wildlife and habitat conservation

$07 / 75$ S. Valente International Status Seeking, Trade, and Growth Leadership

07/74 J. Durieu, H. Haller, N. Querou and P. Solal Ordinal Games

07/73 V. Hahn Information Acquisition by Price-Setters and Monetary Policy

07/72 H. Gersbach and H. Haller Hierarchical Trade and Endogenous Price Distortions

07/71 C. Heinzel and R. Winkler The Role of Environmental and Technology Policies in the Transition to a Lowcarbon Energy Industry

07/70 T. Fahrenberger and H. Gersbach Minority Voting and Long-term Decisions

07/69 H. Gersbach and R. Winkler On the Design of Global Refunding and Climate Change

07/68 S. Valente Human Capital, Resource Constraints and Intergenerational Fairness

07/67 O. Grimm and S. Ried Macroeconomic Policy in a Heterogeneous Monetary Union

07/66 O. Grimm Fiscal Discipline and Stability under Currency Board Systems 
07/65 M. T. Schneider

Knowledge Codification and Endogenous Growth

07/64 T. Fahrenberger and H. Gersbach

Legislative Process with Open Rules

07/63 U. von Arx and A. Schäfer

The Influence of Pension Funds on Corporate Governance

07/62 H. Gersbach

The Global Refunding System and Climate Change

06/61 C. N. Brunnschweiler and E. H. Bulte

The Resource Curse Revisited and Revised: A Tale of Paradoxes and Red Herrings

06/60 R. Winkler

Now or Never: Environmental Protection under Hyperbolic Discounting

06/59 U. Brandt-Pollmann, R. Winkler, S. Sager, U. Moslener and J.P. Schlöder Numerical Solution of Optimal Control Problems with Constant Control Delays

06/58 F. Mühe

Vote Buying and the Education of a Society

06/57 C. Bell and H. Gersbach

Growth and Enduring Epidemic Diseases

06/56 H. Gersbach and M. Müller

Elections, Contracts and Markets

06/55 S. Valente

Intergenerational Transfers, Lifetime Welfare and Resource Preservation

06/54 H. Fehr-Duda, M. Schürer and R. Schubert

What Determines the Shape of the Probability Weighting Function?

06/53 S. Valente

Trade, Envy and Growth: International Status Seeking in a Two-Country World

06/52 K. Pittel

A Kuznets Curve for Recycling

06/51 C. N. Brunnschweiler

Cursing the blessings? Natural resource abundance, institutions, and economic growth

06/50 C. Di Maria and S. Valente

The Direction of Technical Change in Capital-Resource Economics

06/49 C. N. Brunnschweiler

Financing the alternative: renewable energy in developing and transition countries 
06/48 S. Valente

Notes on Habit Formation and Socially Optimal Growth

06/47 L. Bretschger

Energy Prices, Growth, and the Channels in Between: Theory and Evidence

06/46 M. Schularick and T.M. Steger

Does Financial Integration Spur Economic Growth? New Evidence from the First Era of Financial Globalization

05/45 U. von Arx

Principle guided investing: The use of negative screens and its implications for green investors

05/44 Ch. Bjørnskov, A. Dreher and J.A.V. Fischer

The bigger the better? Evidence of the effect of government size on life satisfaction around the world

05/43 L. Bretschger

Taxes, Mobile Capital, and Economic Dynamics in a Globalising World

05/42 S. Smulders, L. Bretschger and H. Egli

Economic Growth and the Diffusion of Clean Technologies: Explaining Environmental Kuznets Curves

05/41 S. Valente

Tax Policy and Human Capital Formation with Public Investment in Education

05/40 T.M. Steger and L. Bretschger

Globalization, the Volatility of Intermediate Goods Prices and Economic Growth

05/39 H. Egli

A New Approach to Pollution Modelling in Models of the Environmental Kuznets Curve

05/38 S. Valente

Genuine Dissaving and Optimal Growth

05/37 K. Pittel, J.-P. Amigues and T. Kuhn, Endogenous Growth and Recycling: A Material Balance Approach

05/36 L. Bretschger and K. Pittel

Innovative investments, natural resources, and intergenerational fairness: Are pension funds good for sustainable development?

04/35 T. Trimborn, K.-J. Koch and T.M. Steger

Multi-Dimensional Transitional Dynamics: A Simple Numerical Procedure

04/34 K. Pittel and D.T.G. Rübbelke

Private Provision of Public Goods: Incentives for Donations

04/33 H. Egli and T.M. Steger

A Simple Dynamic Model of the Environmental Kuznets Curve 